\title{
Alojamento do granito Lavras e a mineralização aurífera durante evolução de centro vulcano-plutônico pós-colisional, oeste do Escudo Sul-riograndense: dados geofísicos e estruturais

\author{
Lavras granite emplacement and gold mineralization during the \\ Sul-riograndense Shield: Geophysical and structural data \\ Maria do Carmo Gastal ${ }^{1 *}$, Francisco José Fonseca Ferreira ${ }^{2}$, \\ Jefferson Ulisses da Cunha², Camila Esmeris ${ }^{3}$, Edinei Koester ${ }^{4}$, \\ Maria Irene Bartolomeu Raposo ${ }^{5}$, Marcos de Magalhães May Rossetti ${ }^{4}$
} development of the post-collisional volcanoplutonic center, west of the
}

\begin{abstract}
RESUMO: A construção do granito Lavras é analisada mediante integraçáo de dados geológicos, geofísicos e estruturais originais e compilados, em consonância com a evoluçấo do centro vulcano-plutônico. Esse centro engloba o complexo intrusivo Lavras do Sul e a sequência traquiandesítica da Formaçấo Hilário $(604-590 \mathrm{Ma})$, ambos formados em posição de antepaís durante o período pós-colisional da Orogênese Dom Feliciano, no oeste do Escudo Sul-riograndense. A análise de estruturas rúpteis e lineamentos magnéticos indica que o vulcanismo teve início próximo ao colapso dessa orogenia, condicionado por sistemas transtensivos dextrais NW-SE a WNW-ESE que invertem para sinistrais com o relaxamento tectônico. A formação do complexo intrusivo, principiando com a intrusão subvulcânica do monzonito Tapera no norte, acompanhou a inversáo no regime de stress regional ao longo de zona de falha $\mathrm{N} 70-75^{\circ} \mathrm{W}$ que o seciona. Ao final, ocorreu o posicionamento do granito Lavras no sul, o qual possui dimensôes modestas $\left(325 \mathrm{~km}^{3}\right)$ e forma tabular (comprimento $-\mathrm{L}$ : espessura $-\mathrm{E} \approx 3: 1$ ) afinando para sul, como deduzido dos dados gravimétricos. Dois domínios composicional-estruturais, equivalentes aos granitos magnesianos centrais (granodiorito e monzogranito) e os ferrosos da borda (sienogranito e feldspato alcalino granito), são definidos pela trama ASM (anisotropia de suscetibilidade magnética). Tais dados, aliados aos de estruturas rúpteis, apontam um pluton multicíclico construído em dois eventos de ressurgência, envolvendo: (1) o lacólito central decorrente do alojamento do granodiorito sob a soleira de monzogranito; e (2) as intrusōes anulares de granitos
\end{abstract}

ABSTRACT: Based on the integration of original and available geological, geophysical and structural data, we assess the construction of the Lavras granite in an evolving volcanoplutonic center. This center encompasses the Lavras do Sul intrusive complex and the Hilário trachyandesitic sequence $(604-590 \mathrm{Ma})$, both formed in the western foreland setting during the post-collisional period of the Dom Feliciano Orogeny, Sul-riograndense Shield. Brittle structures and magnetic lineaments indicate the volcanic activity starting near the orogenic collapse, since it was initially controlled by NW-SE and WNW-ESE-striking dextral transtensive systems that inverted to sinistral during tectonic relaxation. The intrusive complex was formed from the north to the south, with emplacement of the Tapera monzonite and the Lavras granite respectively, following slip change along the $N 70-75^{\circ} \mathrm{W}$ fault zone cutting it across. The granite has moderate dimensions $\left(325 \mathrm{~km}^{3}\right.$ ) and a tabular shape (length $-L$ : thickness $-T \approx 3: 1)$ tapering to the south, as deduced from gravity data. AMS petrofabric (anisotropy of magnetic susceptibility) reinforces two compositional-structural domains in the center and in the border of this granite body, represented by the magnesian terms (granodiorite and monzogranite) and the ferroan ones (syenogranite and alkali feldspar granite) respectively. These data together with brittle structures point to a multistage pluton constructed in two resurgent episodes involving: (1) the central laccolith through the emplacement of granodiorite beneath the monzogranite sill; and (2) the annular

${ }^{1}$ Departamento de Mineralogia e Petrologia, Instituto de Geociências, Universidade Federal do Rio Grande do Sul - UFRGS, Porto Alegre (RS), Brasil. E-mail:maria.gastal@ufrgs.br

2Laboratório de Pesquisas em Geofísica Aplicada, Universidade Federal do Paraná - UFPR, Curitiba (PR), Brasil. E-mail:francisco.ferreira@ufpr.br e prospecgeo@gmail.com ${ }^{3}$ Amarillo Mineração do Brasil Ltda., Belo Horizonte (MG), Brasil. E-mail: camila@amarillogold.com

${ }^{4}$ Instituto de Geociências, Universidade Federal do Rio Grande do Sul - UFRGS, Porto Alegre (RS), Brasil. E-mail: koester@ufrgs.br e marcos_rossetti@hotmail.com 'Instituto de Geociências, Universidade de São Paulo - USP, São Paulo (SP), Brasil. E-mail: irene@usp.br

${ }^{*}$ Autor correspondente.

Manuscrito ID: 30208. Recebido em: 22/11/2014. Aprovado em: 28/01/2015. 
ferrosos, induzidas pela expansão do reservatório epizonal em razão da recarga com magmas máfico-ultramáficos lamprofíricos. O controle estrutural, a distribuiçâao espacial e a associação com diques lamprofíricos corroboram o vínculo da mineralização aurífera com o último episódio de ressurgência em um centro vulcano-plutônico maduro.

PALAVRAS-CHAVE: Pluton ressurgente; Estruturas rúpteis; Tectônica Transtensiva; Lamprófiro; Dados Magnéticos.

\section{INTRODUÇÃO}

O complexo intrusivo Lavras do Sul $(604-590 \mathrm{Ma})$ e a sequência vulcânica da Formação Hilário, portadores de mineralização de $\mathrm{Au}-\mathrm{Cu}(\mathrm{Pb}-\mathrm{Ag})$, ocorrem no oeste do Escudo Sul-riograndense e são pós-colisionais à Orogênese Dom Feliciano (640 - 620 Ma; Silva et al. 2005). O pluton, a seguir designado de granito Lavras, compóe a parte sul do complexo intrusivo. As duas propostas para seu alojamento, subsidência de caldeira em profundidade (Nardi 1984) ou ressurgência pós-colapso (Gastal et al. 2006), são consistentes com um centro vulcano-plutônico. As intrusóes, no primeiro caso, são alojadas durante o decréscimo da pressão interna na câmara magmática (cauldron subsidence; Roberts 1970; Burchardt et al. 2012), enquanto as ressurgentes representam o magma residual que, após a subsidência, retoma o movimento ascendente na supraestrutura vulcânica (Smith \& Bailey 1968; Kennedy et al. 2012).

O posicionamento de intrusóes rasas (profundidade $<8 \mathrm{~km}$ ), controlado por forças internas e condiçôes de stress regional, envolve deslocamento vertical via abatimento do assoalho e/ou soerguimento do teto (Petford et al. 2000; Cruden \& McCaffrey 2001). Deslocamento lateral é restrito à tectônica com componente extensivo importante (Bartley et al. 2008). Processos variáveis no tempo e espaço, como amalgamação de pulsos ou incrementos sucessivos de magma, têm implicaçôes relevantes na exploraçâo de depósitos magmático-hidrotermais associados a corpos intrusivos, pois definem o "como e onde" (Kloppenburg et al. 2010). A conexão entre centros vulcano-plutônicos e zonas de falha transtensivas é reportada em arcos continentais e ambientes pós-colisionais (Acocella \& Funiciello 2010; Pirajno 2010). Quando as atividades ígnea e tectônica são coevas, o reservatório magmático atua como barreira dúctil que segmenta a falha em propagação, modificando o desenvolvimento de estruturas e centro ígneo (Holohan et al. 2008; Dooley \& Schreurs 2012).

A reconstituiçấo dos processos formadores de corpos intrusivos requer, portanto, a investigação conjunta do desenvolvimento petrológico e estrutural (padróes de propagaçáo segundo parâmetros internos e externos). Adotando essa linha para o granito Lavras, são abordados:

1. o arcabouço estrutural fundamentado em imagens de sensores remotos, mapas aeromagnetométricos e análise de estruturas rúpteis; e intrusions of ferroan granites, induced by expansion of the high-level reservoir due to recharge with lamprophyric mafic-ultramafic magmas. Its structural control, spatial distribution and association with lamprophyric dykes attest the link of gold mineralization with the last resurgent episode in a mature volcanoplutonic center.

KEYWORDS: Resurgent Pluton; Brittle Structures; Transtensive Tectonic; Lamprophyre; Magnetic Data.

2. os mecanismos de alojamento com a integração geologia-geofísica, incluindo petrotrama (Raposo \& Gastal 2009) e gravimetria (Cunha et al. 2008).

O propósito é avaliar o vínculo deste granito com a tectônica rúptil, o vulcanismo coevo e a mineralização aurífera, consoante a evolução do centro vulcano-plutônico pós-colisional.

\section{MATERIAIS E MÉTODOS}

Alinhamentos e lineamentos tectônicos foram extraídos do modelo digital de elevação, derivado do SRTM (Shuttle Radar Topography Mission, NASA-USGS, 2000; resolução de $90 \mathrm{~m}$ ) e da imagem de satélite ASTER (AST-L1B-003-05112002134359-05222002151702), bandas do visível ao infravermelho de ondas curtas (VNIR-SWIR, resoluçáo de $15 \mathrm{~m}$ ). São utilizados dados magnetométricos dos projetos aerogeofísicos Escudo do Rio Grande do Sul (CPRM 2010) e Lavras do Sul (Amarillo Mineração do Brasil Ltda. 2007, relatório interno), incluindo a gamaespectrometria do último. Os dois levantamentos foram obtidos segundo linhas de voo N-S com altitude de $100 \mathrm{~m}$ e espaçamento médio de, respectivamente, $500 \mathrm{~m}$ (intervalo de amostragem de $6-7 \mathrm{~m}$ ) e $100 \mathrm{~m}$ (intervalo de amostragem de $8-10$ e $80-100 \mathrm{~m}$ ). Os dados originais foram interpolados em malha regular com dimensão de 100 e $20 \mathrm{~m}$ (1/5 do espaçamento das linhas de voo), pelo método da curvatura mínima. O mapa do campo magnético anômalo (CMA), obtido a partir do sinal original previamente micronivelado e subtraído do modelo do IGRF (International Geomagnetic Reference Field para a época do levantamento), foi reduzido ao polo (RTP) para inclinação e declinação, respectivamente, de $-37^{\circ} 13^{\prime}$ e- $13^{\circ} 28^{\prime}$ e de $-36^{\circ} 33^{\prime}$ e $-12^{\circ} 57^{\prime}$. Aos dados resultantes CMA-RTP, foram aplicados filtros de continuaçáo para cima $(500-1.000$ e $200-500 \mathrm{~m})$ que removem os sinais de pequeno comprimento de onda, reduzem o ruído e salientam estruturas mais profundas. Após essas etapas, foram aplicadas técnicas de realce como amplitude do sinal analítico (ASA) (Nabighian et al. 2005), derivadas verticais (Milligan \& Gunn 1997) e gradiente horizontal total (GHT) (Cordell \& Grauch 1985). Quando gradientes e anomalias de 
diferentes níveis crustais são comparados em mapas magnéticos continuados, é possível qualificar em $3 \mathrm{D}$ a geometria e natureza de litologias e estruturas. Valores de suscetibilidade magnética aparente, referidos na interpretação, equivalem à média de medidas em afloramento.

A arquitetura tectônica é realçada pela correspondência entre lineamentos tectônicos e magnéticos, porém os últimos podem também refletir paleovales com lava, pequenas intrusóes ou condutos de magma. Zonas de falha foram identificadas pelas feiçôes morfológicas e estruturas rúpteis, utilizando indicadores cinemáticos diversos (Petit 1987; Hippolyte et al. 2012). As populaçôes de falhas e mesofalhas (cm-m; Hancock 1985) foram separadas pelo método dos diedros retos P\&T (Angelier \& Mechler 1977), no programa Faultkin 5.6.3 (Marret \& Allmendinger 1990; Allmendinger et al. 2012), conferindo peso menor ao vetor deslocamento deduzido das relaçóes angulares de fraturas Riedel. O método consiste em determinar o vetor que coincide com o maior número de quadrantes $\mathrm{P}$ (contraçáo) de um conjunto de falhas, a fim de estimar os componentes principais de strain (X, Y e Z), que aproximam os de stress. Além de eventos tectônicos, os regimes cinemáticos podem indicar fases sucessivas, partição da deformação ou flutuaçóes no campo de stress, de modo que reorientaçóes e ramificaçôes são avaliadas em estereogramas dos eixos $\mathrm{P}$.

O mapa de anomalias Bouguer do granito, em malha regular de 500 x $500 \mathrm{~m}$, foi gerado a partir dos dados gravimétricos corrigidos (Gastal et al. 2006), e a separação regional-residual resultou da subtração de uma superfície de tendência de primeiro grau (Cunha et al. 2008). Esses autores utilizam a técnica de inversão gravimétrica de Cordell e Henderson (1968) na obtenção das profundidades do assoalho em relação a um plano de referência, calculadas para contraste específico de densidade. Os valores de densidade em amostras de rocha equivalem à diferença de peso no ar e na água.

\section{CONTEXTO GEOLÓGICO}

\section{Região de Lavras do Sul}

A região em estudo está localizada no Bloco São Gabriel, próximo ao Bloco Taquarembó (Fig. 1A). Esses dois terrenos do oeste do Escudo Sul-riograndense consistem, respectivamente, de associaçóes de arco magmático toniano-criogeniano $(900-700 \mathrm{Ma})$ e da borda do Craton Rio de La Plata. Representam o antepaís durante a Orogênese Dom Feliciano, ocorrida no leste e cujo clímax colisional, entre 640 - 620 Ma (Silva et al. 2005), é marcado por zonas de cisalhamento dúctil subverticais $\mathrm{N} 30-40^{\circ} \mathrm{E}$ sinistrais. As unidades do embasamento toniano-criogeniano aflorantes a oeste ocorrem em dois setores, sul e norte (Figs. 1B e $2 \mathrm{~A}$ ). No setor sul, as unidades mais antigas exibem trama desenvolvida segundo zonas de cisalhamento dúctil E-W a ENE-WSW de médio ângulo (Fernandes et al. 1995), que evoluem a dúctil-rúpteis subverticais (Figs. 2A, 2C e 2D). Estas unidades são representadas pela sequência metassedimentar da Formação Arroio Marmeleiro (Fig. 1B) e pelo Complexo Máfico-ultramáfico Cerro Mantiqueira (UFRGS 2004; CPRM 2007), os quais estão tectonicamente imbricados a ortognaisses do Complexo Imbicuí, por sua vez, intrudidos pelo metatonalito Meireles (Fig. 2A). O granodiorito Fazenda do Posto é tardi-tectônico ao cisalhamento subvertical. Neste, a foliação magmática e a milonítica são subconcordantes segundo ENE-WSW no sul e inflectem para N-S e NW-SE ao norte (Figs. 2A e 2C). No setor norte, predominam rochas graníticas condicionadas por zonas transcorrentes dúctil-rúptil subverticais $\mathrm{N} 50-60^{\circ} \mathrm{E}$ sinistrais (Figs. 2A e 2B). O diorito Arroio Branquilho e o tonalito Arroio dos Carros são, respectivamente, pré- e sin-tectônicos (UFRGS 2003). Ortognaisses são restritos, e as sequências supracrustais do Complexo Metamórfico Vacacaí afloram no extremo noroeste (Fig. 1B). Rochas supracrustais correlatas constituem o alto do embasamento no leste.

A Bacia do Camaquã, na metade leste (Fig. 1B), inclui sequências sedimentares e vulcânicas ediacaranas a cambrianas. A Formação Maricá, na base, tem o limite inferior definido pela idade U-Pb em zircáo de $630 \pm 3 \mathrm{Ma}$ (seixo de rocha piroclástica; Borba et al. 2008). Consiste de arenitos arcoseanos a conglomeráticos com nível intermediário de pelitos, que afloram a sul e a norte do complexo intrusivo (Fig. 2A). Os estratos, com direção NNW-SSE a NNE-SSW e mergulho suave para leste, estão basculados e rotados próximo a falhas NW-SE e NE-SW (Figs. 2A e 2E). No sul, os arenitos basais estão a oeste e os pelitos a leste (UFRGS 2004), onde os estratos mostram maior movimentação tectônica.

A Formação Hilário inclui lavas traquiandesíticas intercaladas a rochas particuladas diversas (Lima 1995), em estratos NNW-SSE, com mergulho suave para nordeste (Fig. 2F). Camadas de direção NW-SE e alto ângulo para sudoeste ocorrem a nordeste e sudeste do monzonito Tapera (Figs. 2A e 2F). Esta sequência é intrudida por stocks de quartzo monzonito porfirítico e pelo granito peralcalino Estrela (Fig. 2A). Idades Ar-Ar em plagioclásio para rochas traquiandesíticas variam entre $590 \pm 6 \mathrm{Ma}$ e $586 \pm 8 \mathrm{Ma}$ (Janikian et al. 2008). Diques intermediários correlatos, de direção NW-SE a NNW-SSE e NE-SW subordinada, estão concentrados nos arredores do complexo intrusivo a norte (Fig. 3). Predominam traquiandesitos variados e quartzo monzonito, com espessartito e diorito subordinados.

Sequências sedimentares mais jovens incluem a Formação Santa Fé e o Grupo Santa Bárbara (Fig. 1B), para o qual 
Bica et al. (2013) obtiveram a idade média U-Pb em zircáo de $558 \pm 13 \mathrm{Ma}$ (conglomerado e arenito). A primeira, na base, corresponde à deposição em pequenos grabens no final do período de soerguimento regional (Borba et al. 2008), contemporâneo ao vulcanismo félsico da Formação Acampamento Velho (575 - $560 \mathrm{Ma}$ ), inexpressivo na região. Nas duas sequências, os estratos são sub-horizontais, com basculamento restrito (Figs. 2A e 2F). O complexo intrusivo em estudo e os granitos Jaguari $(569 \pm 6 \mathrm{Ma}, \mathrm{U}-\mathrm{Pb}$ em zircão; Gastal et al. 2010) e Fazenda Saibro são coevos, respectivamente, às formaçóes Hilário e Acampamento Velho (Figs. 1B e 2A).

\section{Complexo intrusivo Lavras do Sul}

O complexo intrusivo, alongado na direçáo N-S (10,3 x 16,2 km; Fig. 2A), inclui o monzonito Tapera (MT) no norte e o granito Lavras no sul. O primeiro consiste de diorito e monzodiorito com foliação magmática subvertical na borda externa, e monzonito pouco foliado no centro (UFRGS 2003). Quartzo monzonito porfirítico (QMP), em pequenos stocks, exibe contato brusco com os termos da borda e gradativo com aquele central. O monzodiorito Arroio do Jacques (MAJ), em corpo alongado e estreito entre o monzonito e o granito, é também secionado pelo QMP.
O granito Lavras (GL), grosseiramente circular em planta $(12,2 \times 10,4 \mathrm{~km})$, intrude granitoides no oeste-sudoeste e as formaçôes Hilário (leste) e Maricá (sul-sudeste), sendo secionado no oeste pelo granito Jaguari (Fig. 2A). Lavas e tufos estão intensamente oxidados no contato, enquanto metamorfismo termal de baixo grau é localizado nos arenitos (Fig. 3A). O granito exibe zonação composicional reversa, contendo termos texturalmente isotrópicos, preferencialmente magnesianos no centro e ferrosos na borda (Fig. 4). Os termos centrais incluem biotita granodiorito circundado por hornblenda-biotita monzogranito, que grada a hornblenda-biotita sienogranito com geoquímica mista na porção intermediária. Biotita-hornblenda sienogranito e feldspato alcalino granito compóem aqueles da borda (Fig. 2A). $\mathrm{O}$ contato entre eles é gradativo ou brusco, sem registros de margem resfriada. O monzogranito é comum em porçôes decamétricas envoltas pelo granodiorito ou sienogranito intermediário, e o último é intrudido pelos termos da borda no nordeste-leste. A granulaçáo em todos varia de grossa a média com tipos equigranulares ou seriados. No granodiorito, contudo, a fácies seriada dominante grada à porfirítica grossa e fina, em domínios orientados segundo NE-SW (Fig. 2A). Enclaves microgranulares máficos são comuns, exceto no granodiorito.

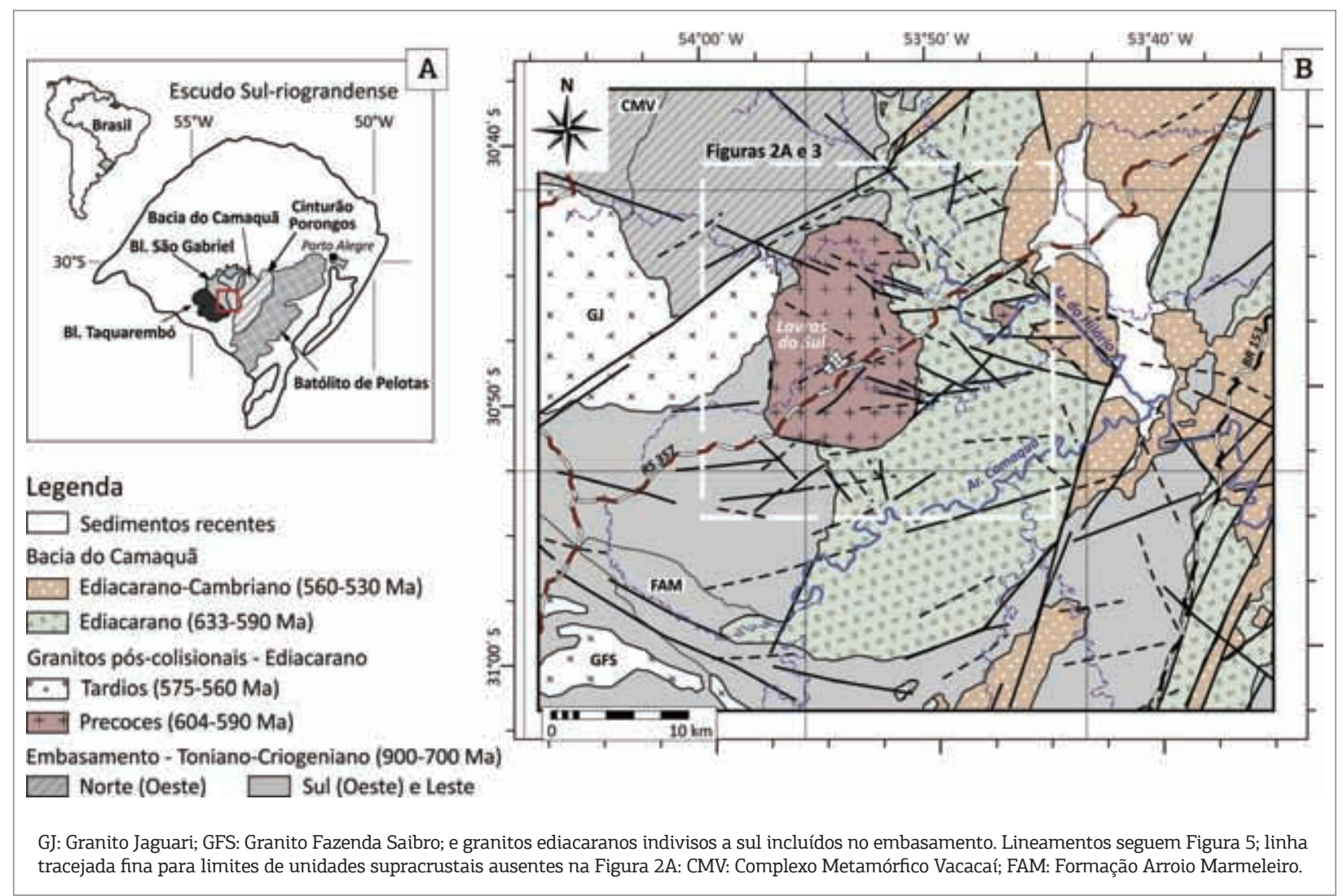

Figura 1. (A) Compartimentos do Escudo Sul-riograndense; (B) Mapa geológico simplificado de Lavras do Sul (Porcher \& Lopes 2000; CPRM 2007; linha pontilhada fina para coordenadas UTM, datum SAD69). 


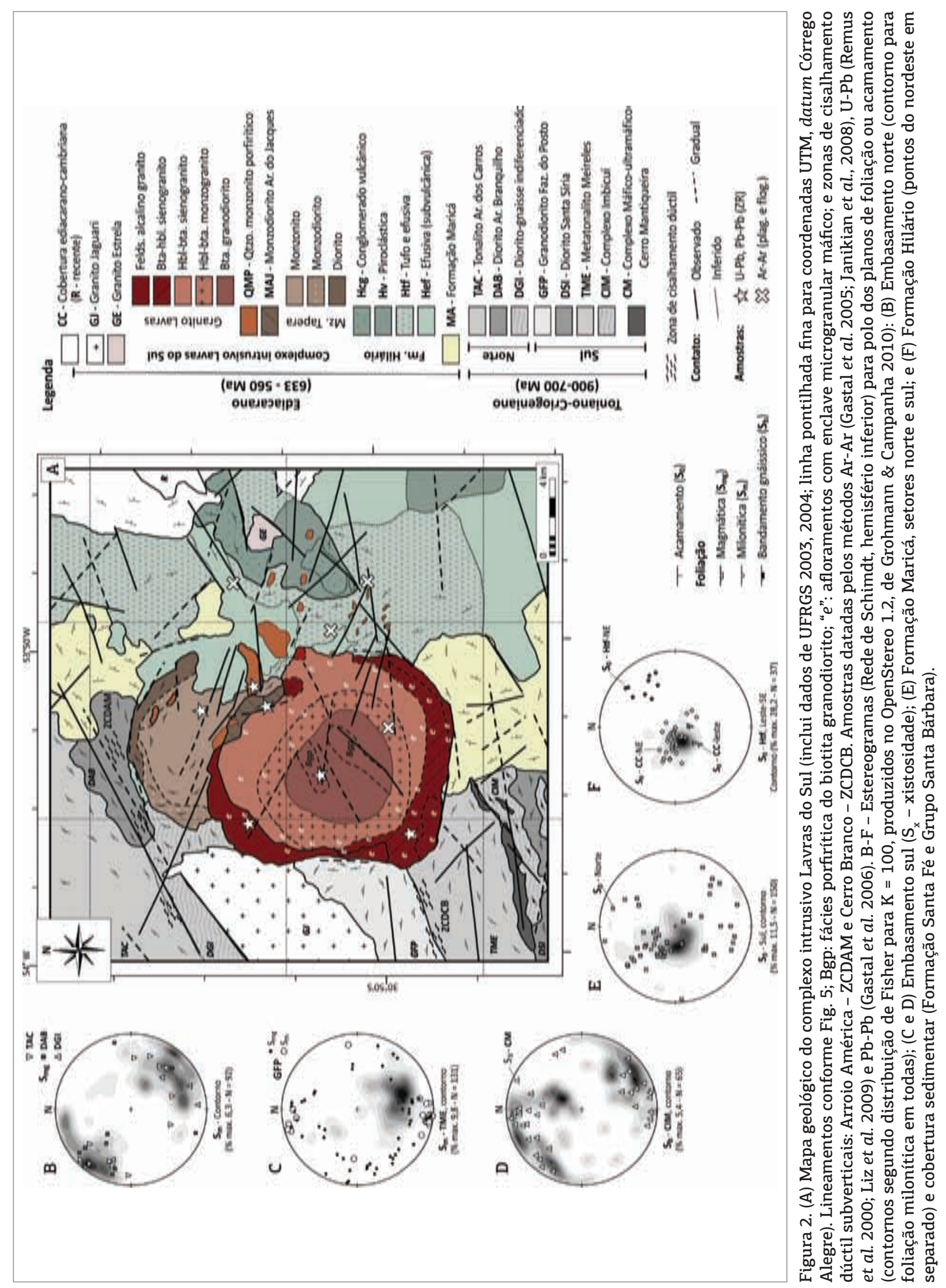


As relaçôes de contato entre o GL e MT-MAJ são diversificadas. O sienogranito intermediário faz contato tectônico com o MAJ. O feldspato alcalino granito intrude este e o MT, e forma apófises e diques a oeste e sul-sudeste (Fig. 3A). Idades isotópicas em zircão, revistas por Gastal et al. (2006), mostram que granodiorito (U-Pb, $601 \pm 2 \mathrm{Ma}$; Remus et al. 2000), sienogranito da borda (Pb-Pb, $598 \pm 3 \mathrm{Ma})$ e rochas monzonito-dioríticas (Pb-Pb, MT - 601 \pm 5 Ma e MAJ $599 \pm 7 \mathrm{Ma}$ ) registram evento magmático expressivo ao redor de $600 \mathrm{Ma}$. Duas populaçóes de idade U-Pb em zircáo, cuja interpretação é ainda controversa, são obtidas para o feldspato alcalino granito $(599 \pm 2 \mathrm{Ma}$ e $586 \pm 3 \mathrm{Ma}$; Remus et al. 2000) e quartzo monzonito porfirítico (607 $\pm 6 \mathrm{Ma}$ e $587 \pm 4 \mathrm{Ma}$; Liz et al. 2009). Diques máfico-ultramáficos lamprofíricos de direção WNW-ESE a NW-SE ocorrem indistintamente no GL (Fig. 3), sendo frequentes junto às zonas mineralizadas em testemunhos de sondagem. Para uma amostra de minete aflorante, a idade Ar-Ar em flogopita é de $590 \pm 2 \mathrm{Ma}$ (Gastal et al. 2005). Diques félsicos incluem dacito nos granitos centrais (NE-SW e WNW-ESE) e riolito mais jovem no noroeste (NNE-SSW).

\section{Distritos mineiros}

Os prospectos, no distrito aurífero de Lavras do Sul (DALS) (Fig. 3A), estão distribuídos no granito Lavras $(\mathrm{Au} \pm \mathrm{Cu} \pm \mathrm{Ag})$ e na sequência vulcânica $(\mathrm{Cu}-\mathrm{Au}-\mathrm{Pb} \pm \mathrm{Ag})$. A zonalidade da mineralização (Au versus. $\mathrm{Cu}-\mathrm{Pb}$ ) tem sido atribuída à posição relativa ao granito (Nardi \& Lima 1988), onde o minério (0,3 - $16 \mathrm{~g} /$ ton de Au) consiste de pirita aurífera e Au livre subordinado, associados à blenda e galena em veios de quartzo e na forma disseminada. A mineralização varia do tipo pórfiro no granito a epitermal na sequência vulcânica (Bongiolo 2006), todavia Kaul e Rheinheimer (1974) descrevem controle estrutural similar em ambos, segundo direçóes preferenciais WNW-ESE a ENE-WSW e N50-60 $\mathrm{W}$ sinistrais com variaçóes localizadas $\left(\mathrm{N} 40-70^{\circ} \mathrm{E}\right.$ dextral e $\left.\mathrm{N} 20-30^{\circ} \mathrm{W}\right)$. Controle

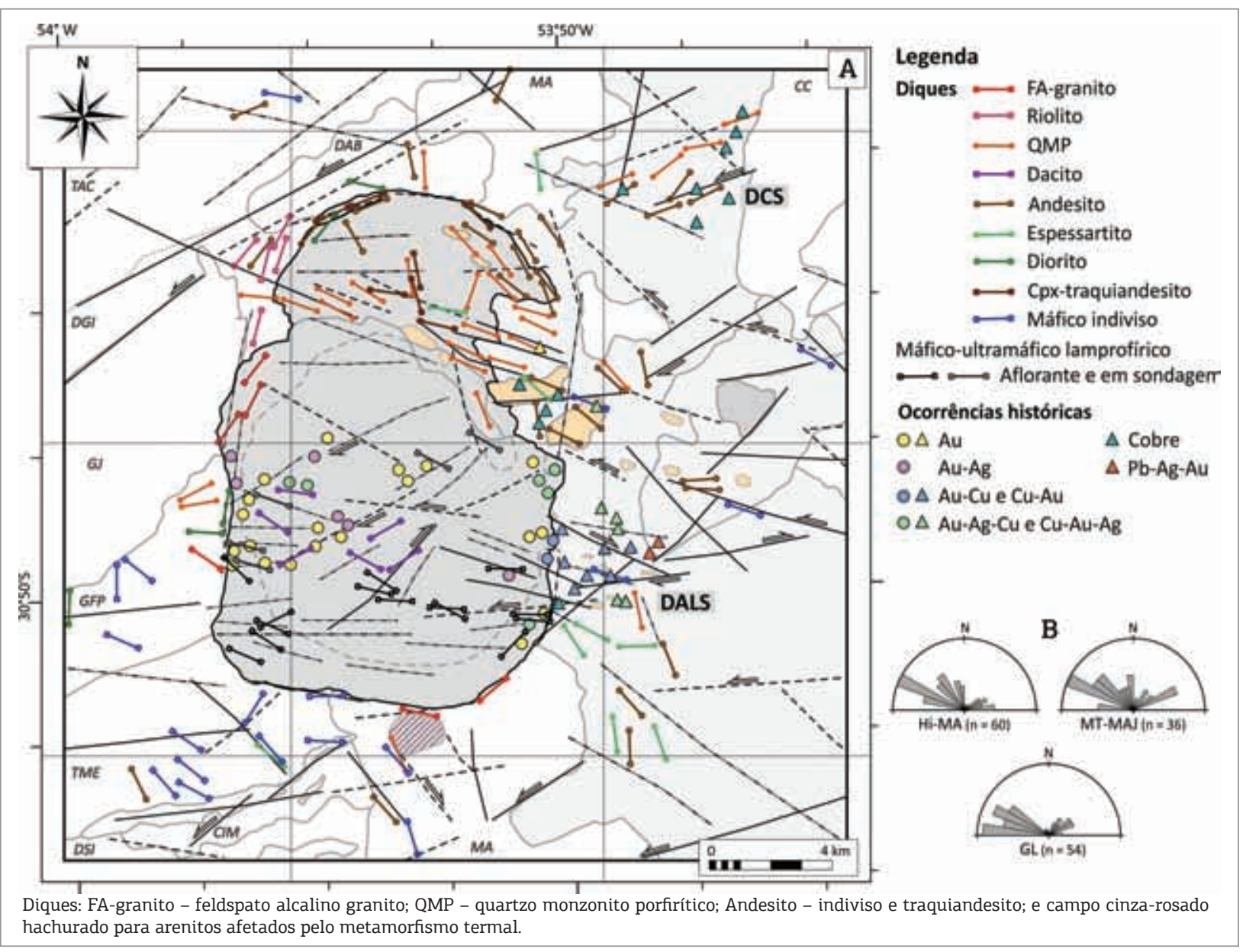

Figura 3. (A) Mapa simplificado realçando as unidades do centro vulcano-plutônico (contatos e coordenadas seguem Fig. 2A, e lineamentos Figs. 6 e 10). Ocorrências históricas de metais no granito (círculo) e na sequência vulcânica (triangulo), distribuídas nos distritos aurífero de Lavras do Sul - DALS (Kaul \& Rheinheimer 1974) e cuprífero do Seival - DCS (Reischl 1978); (B) Diagramas de rosetas para direção de diques nas formações Hilário e Maricá (Hi-MA), no monzonito Tapera e monzodiorito Arroio do Jacques (MT-MAJ) e no granito Lavras (GL). 
distinto é advogado por Reischel (1978) para o distrito cuprífero do Seival, na mesma sequência a norte (DCS - Fig. 3A), onde predominam as direçóes NNE-SSW a NNW-SSE e NE-SW.

\section{TECTÔNICA RÚPTIL REGIONAL}

\section{Lineamentos tectônicos}

Lineamentos longos e densos ocorrem na metade leste, sendo limitados no oeste pelo sistema Segredo-Cerro Alegre (Figs. 5A, 5C e 5D). Esses lineamentos representam zonas de falha sinistrais $\mathrm{N} 15-25^{\circ} \mathrm{E}$ que controlam os limites entre unidades da Bacia do Camaquã e dessas com o embasamento (Fig. 1B). A Z. F. Cerro dos Cabritos de direção N45-55E a $\mathrm{N} 65^{\circ} \mathrm{E}$, mais a oeste, condiciona graben estreito e desloca o granito Jaguari com movimento lateral esquerdo. Direçóes similares a leste são interrompidas pelos primeiros (e.g., Z. F. Rincão dos Mouras). Os demais lineamentos, igualmente interrompidos, incluem aqueles $\mathrm{N} 80-85^{\circ} \mathrm{E}$ até $\mathrm{N} 70-75^{\circ} \mathrm{E}$ expressivos a sul-sudeste (Fig. $5 \mathrm{~A}$ e $5 \mathrm{D}$ ), e N50-70 $\mathrm{W}$ espaçados, longos e contínuos no oeste (Fig. 5B). As estruturas ENE-WSW limitam as unidades do embasamento e secionam as formaçóes Hilário e Maricá (Figs. 1B). Falhas NW-SE a WNW-ESE, subparalelas à Z. F. Suspiro-Linhares, coincidem com o Lineamento de Ibaré. Esse lineamento, interpretado como limite entre os dois terrenos geológicos, representa zona de cisalhamento dúctil-rúptil subvertical dextral, reativada em regime rúptil sinistral (Fernandes et al.

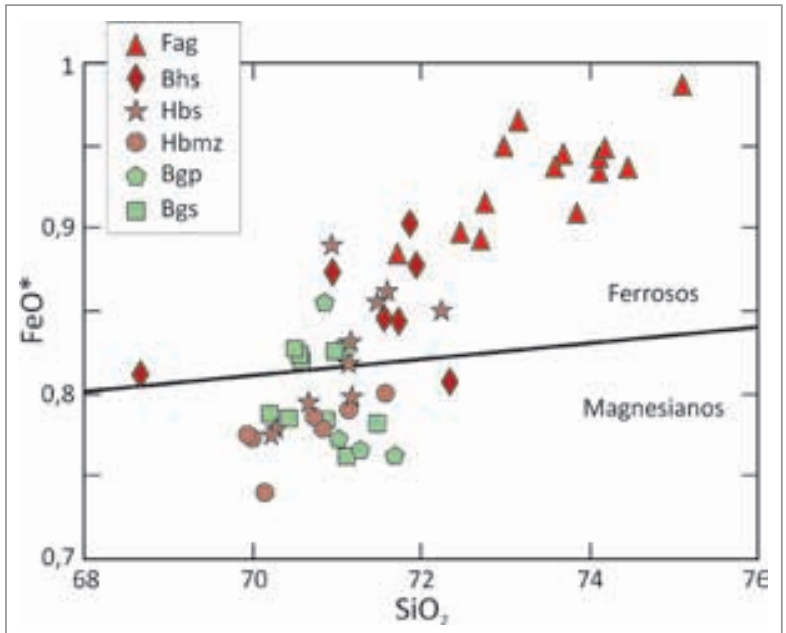

Granitos: Fag: feldspato alcalino granito; Bhs: biotita-hornblenda sienogranito; Hbs: hornblenda-biotita sienogranito; Hbmz: hornblenda-biotita monzogranito; e Bgp e Bgp: biotita granodiorito porfirítico e seriado, respectivamente.

Figura 4. Diagrama FeO* $\left(=\mathrm{FeO}_{\mathrm{t}} /\left(\mathrm{FeO}_{\mathrm{t}}+\mathrm{MgO}\right)\right.$ vs. $\mathrm{SiO}_{2}$ para o granito Lavras, exibindo a classificação dos granitos em ferrosos e magnesianos segundo Frost et al. (2001).
1992). As zonas de falha Passo das Carretas (N55-60W) e Palma-Jacques (N70-75 $\mathrm{W})$ se interceptam a leste-nordeste, e a última seciona o complexo intrusivo (Fig. 5B).

\section{Dados magnetométricos}

No embasamento a oeste, lineamentos magnéticos ENE-WSW a E-W pouco espaçados, estreitos e contínuos caracterizam o setor sul, diferenciando-o daquele do norte marcado por amplitude do sinal analítico mais elevada (Figs. 6A e 6B). A Formação Hilário exibe padrão contrastante relativo às sequências sedimentares, com sinal heterogêneo nos mapas ASA-GHT (Figs. 6B e 6C), relevo mais acentuado naquele da primeira derivada vertical (Fig. 6D) e anomalias variadas, estando as principais em seus limites. No entorno do complexo intrusivo, sobressaem três anomalias magnéticas com amplitude elevada (700 - $500 \mathrm{nT})$, condicionadas por estruturas WNW-ESE a ENE-WSW (Fig. 6B). Comprimento de onda moderado em duas, "a" e "c" $(1,2-1,5 \mathrm{~km})$, indica fontes mais profundas. Valores de suscetibilidade magnética aparente, sobre a primeira, variam em amplo intervalo nos dioritos encaixantes e fácies da borda do monzonito Tapera (35 a $190^{*} 10^{-3}$ SI e 15 a $60^{*} 10^{-3}$ SI, respectivamente). Variação similar é registrada apenas nas encaixantes do granito Lavras (e MAJ) sobre as anomalias "b" (15 a 130* $10^{-3}$ SI em tufos e MT) e "c" (4 a 50* $10^{-3}$ SI em arenitos). A julgar por estes dados, os eventos causadores das anomalias "a" e "b" seriam concomitantes ou posteriores ao monzonito, e os daquelas " $b$ " e "c" anteriores ao granito.

Altos magnéticos nos mapas GHT-RTP (Fig. 6C e veja Fig. 10), em cristas alongadas irregulares NE-SW a NNE-SSW nos limites do granito a leste, apontam condutos de magma. Feiçóes similares ocorrem ao longo da Z. F. Cerro Alegre (N15-20 E) e daquela ENE-WSW, ambas no limite da sequência vulcânica, e também em segmentos da Z. F. Palma-Jacques (N70-75 $\left.{ }^{\circ} \mathrm{W}\right)$. Altos magnéticos mais largos e difusos, de direção E-W a ENE-WSW, sobressaem na zona de transferência desta falha, sugerindo duplex sinistral (Fig. 6). A Z. F. Cerro dos Cabritos equivale a lineamento magnético expressivo, apesar do menor contraste petrofísico no interior do granito Jaguari. Nas proximidades, a $Z$. F. Passo das Carretas (N55-60 $\mathrm{W}$ ) é expressa por gradiente linear abrupto com amplitude moderada a alta.

\section{Sistemas tectônicos regionais}

\section{Estruturas rúpteis}

Estruturas rúpteis, em nível regional (Fig. 7A), exibem alto ângulo $\left(>60^{\circ}\right)$ e obliquidade baixa a moderada $\left(<30-40^{\circ}\right)$. No granito Jaguari equivalem às direçóes $\mathrm{N} 40-50^{\circ} \mathrm{E}$ a N15-25 $\mathrm{E}$ sinistrais, e antitéticas $\mathrm{N} 30-40^{\circ} \mathrm{W}$ (Fig. $7 \mathrm{~B}$ ), que confirmam a Z. F. Cerro dos Cabritos como transcorrência sinistral 


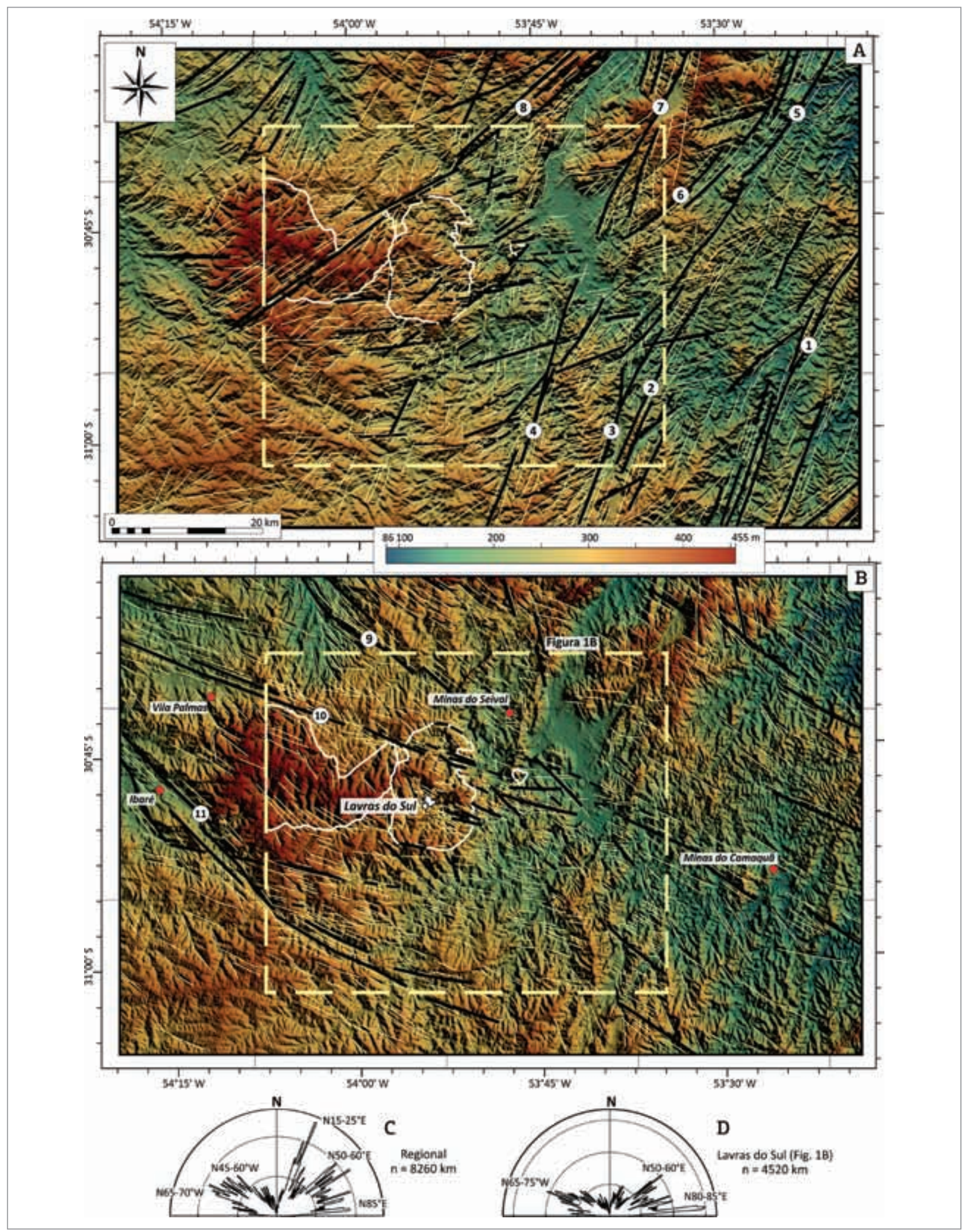

Figura 5. Modelo digital de elevação (MDE-SRTM; coordenadas seguem Fig. 1B), exibindo alinhamentos (linha amarela fina) e lineamentos tectônicos regionais (linha preta grossa contínua, e tracejada para subordinado). Relevo sombreado com filtros de iluminação direcional: (A) NE-SW (Az $0^{\circ}$ ); e (B) NW-SE (Az 60). Zonas de falha (Ribeiro et al. 1966; Ribeiro 1978): 1 - Tapera Emiliano; 2 - Lichiguana; 3 - Passo dos Enforcados; 4 - Cerro Alegre; 5 - Angélica (ou dos Lopes); 6 - Rincão dos Mouras; 7 - Segredo; 8 - Cerro dos Cabritos; 9 - Passo das Carretas (UFRGS 2003); 10 - Palma-Jacques (neste trabalho) e 11 - Suspiro-Linhares. Histograma circular para alinhamentos (intervalos de 50 e 30 km): (C) Regionais; e (D) Lavras do Sul. 


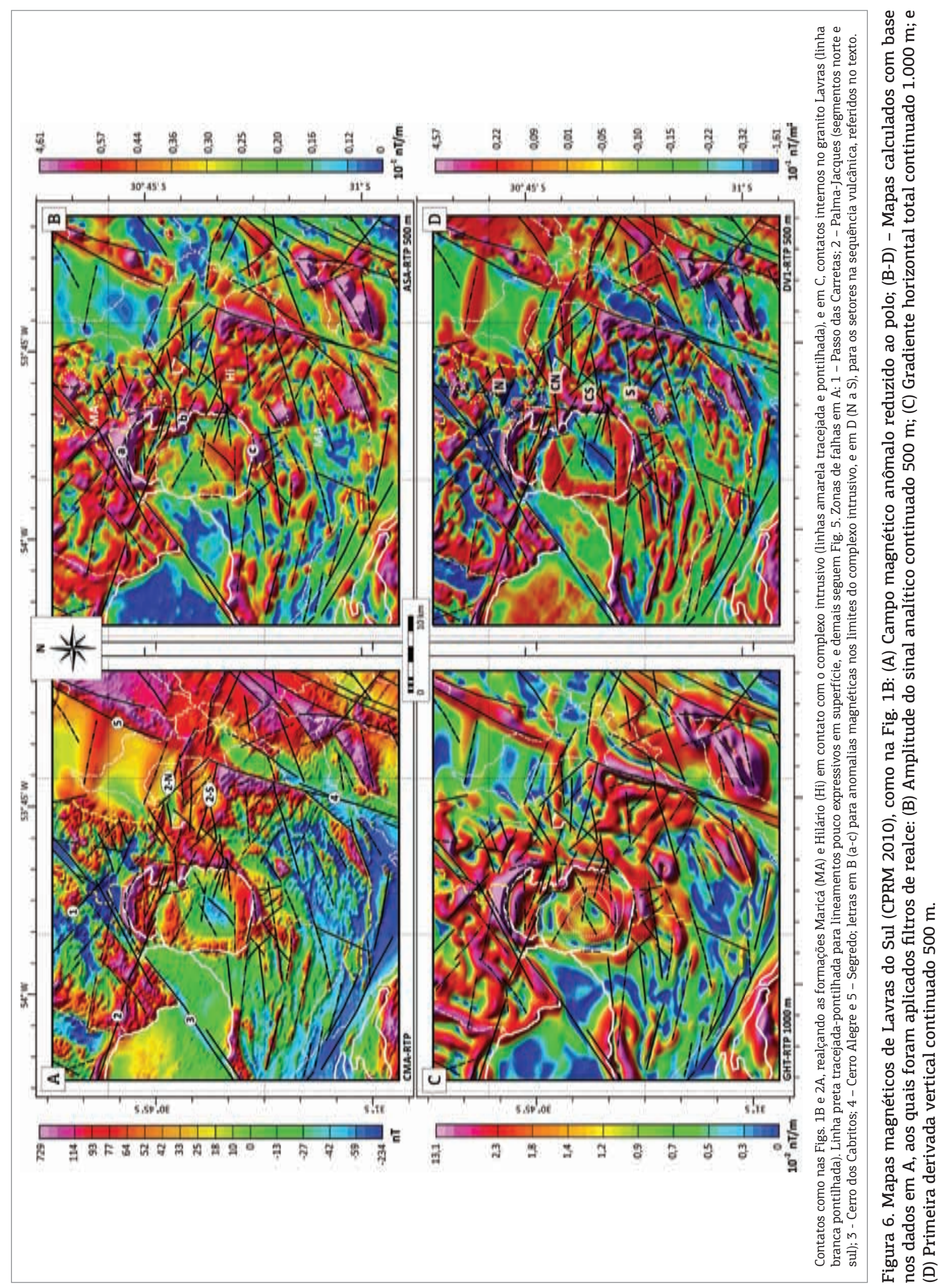




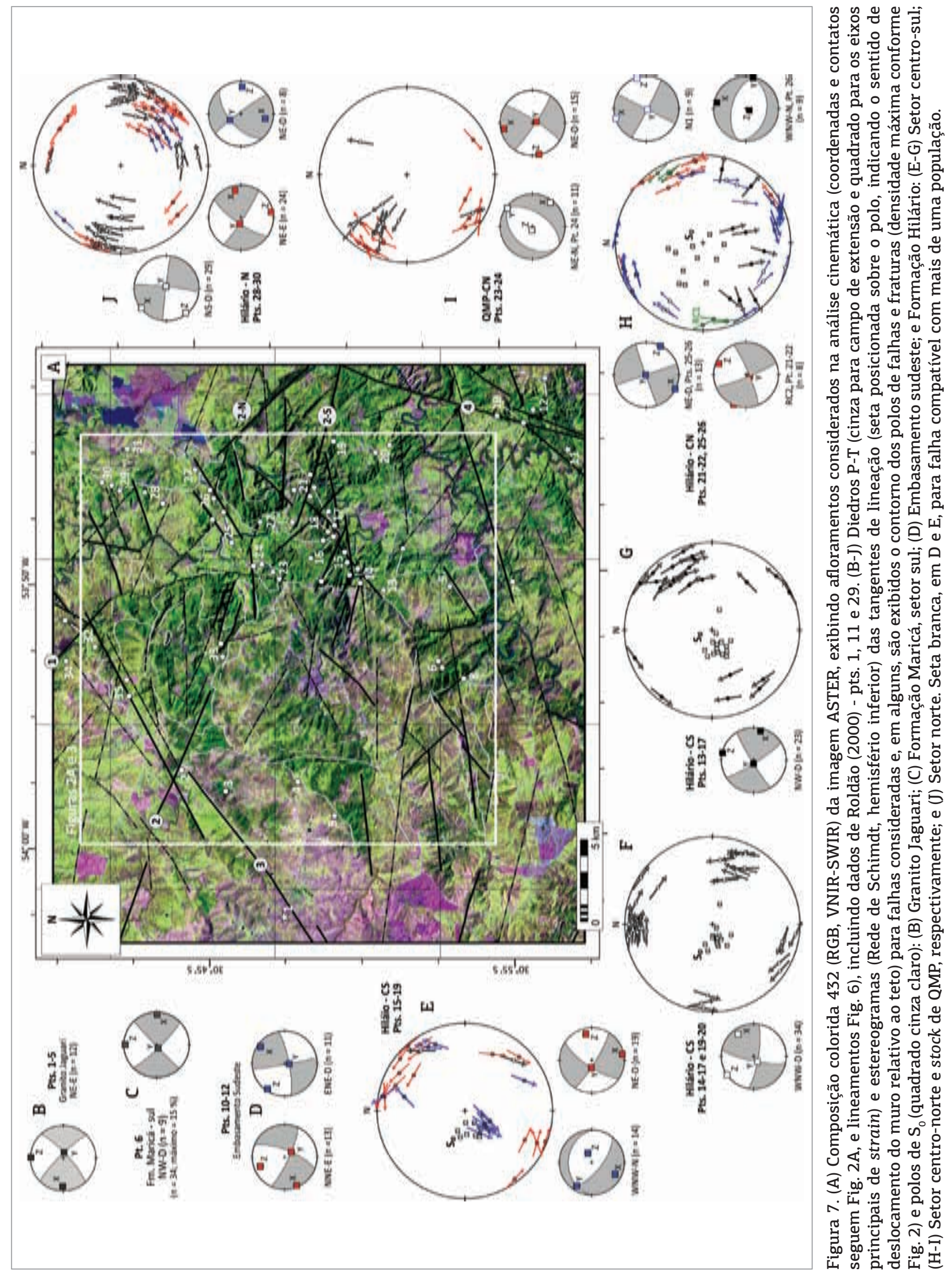


$\mathrm{N} 45^{\circ} \mathrm{E}$ SE. A Formação Maricá, no sul, é afetada por falhas dextrais $\mathrm{N} 25-30^{\circ} \mathrm{W}$ a N50-60 $\mathrm{W}$ e sinistrais N45-65 ${ }^{\circ} \mathrm{E}$ (Fig. $7 \mathrm{C}$ ). Duas populaçóes de falhas, no embasamento a sudeste, sugerem sistema transcorrente dextral $\mathrm{N} 79^{\circ} \mathrm{E} / \mathrm{SE}$ mais antigo, marcado por intensa cataclase, planos com estrias sobrepostas e dobras de arrasto subordinadas. Este é interrompido por estruturas rasas $\mathrm{N} 20-50^{\circ} \mathrm{E}$ (fraturas densas e duplex), restritas ao lineamento da Z. F. Cerro Alegre (Fig. 7D).

Os dados na Formação Hilário são tratados em setores de acordo com os principais lineamentos (Fig. 6D). São frequentes planos de falha com superposição de estrias, zonas de cataclase e fraturas densas, associados a brechas e hidrotermalismo (Fig. 8). Nos setores ao sul (CS e S - Fig. 6D), sobressaem três populaçóes de falha lateral. Aquelas dextrais $\mathrm{N} 40-60^{\circ} \mathrm{W}$ a $\mathrm{N} 10-35^{\circ} \mathrm{W}$ e as subsidiárias $\mathrm{N} 50-75^{\circ} \mathrm{E}$ sinistrais constituem a população mais antiga (Fig. $7 \mathrm{G}$ ), como apontam relaçóes de interseção e estrias superpostas. A segunda inclui estruturas dextrais $\mathrm{N} 75-85^{\circ} \mathrm{W}$ a N80-90 ${ }^{\circ}$ E (Fig. $7 \mathrm{~F}$ ), que predominam no centro-sul e estão associadas às antitéticas $\mathrm{N} 05-30^{\circ} \mathrm{E}$. As duas populaçóes são sobrepostas por falhas normais de alto ângulo (Figs. 8A a $8 \mathrm{C}$ ) e interrompidas por aquelas sinistrais $\mathrm{N} 60-80^{\circ} \mathrm{W}$ a $\mathrm{N} 35-45^{\circ} \mathrm{W}$ e dextrais $\mathrm{N} 45-65^{\circ} \mathrm{E}$ (Fig. $7 \mathrm{E}$ ). Esse terceiro conjunto é também sobreposto ou coevo a falhas normais de alto ângulo para oeste-sul ou norte-leste (Figs. 7E e 8D). Em ignimbritos, sobrepostos a sedimentos finos vulcanogênicos, falhas normais NW-SE discretas de baixo ângulo para norte são atribuídas à deformação frágil facilitada por materiais menos competentes na base (pt. 18; Figs. 7E e $8 \mathrm{E})$. Isso é comum após alojamento e resfriamento deste tipo de rocha (Catalano et al. 2014).

Estruturas rúpteis variadas caracterizam o setor centro-norte, equivalente à área de transferência da Z. F. Palma-Jacques (CN - Fig. 6D). Ao longo do lineamento NE-SW (pts. 25-26 - Fig. 7A), predominam falhas dextrais $\mathrm{N} 55-75^{\circ} \mathrm{E}$, interrompidas pelas normais de alto a moderado ângulo para norte. Estruturas N20-45E (N1 - Fig. $7 \mathrm{H})$, parcialmente compatíveis, ocorrem próximo ao stock de quartzo monzonito (QMP), enquanto aquelas $\mathrm{N} 15-45^{\circ} \mathrm{W}$ a leste são mais variadas (RC1 e 2). No stock de QMP (Fig. 7I), as falhas dextrais $\mathrm{N} 20-30^{\circ} \mathrm{E}$ a N45-60 $\mathrm{E}$ e antitéticas $\mathrm{N} 50-70^{\circ} \mathrm{W}$ interceptam as normais NE-SW de alto a moderado ângulo para sudeste (Figs. 8F e 8G). No setor norte (N - Fig. 6D e 7J), duas populaçóes com moderado a baixo ângulo comum confirmam os sistemas tectônicos referidos por Roldão (2000). Aquele NE-SW sinistral, mais antigo, definido pelas direçôes $\mathrm{N} 40-55^{\circ} \mathrm{E}$ a N15-30 $\mathrm{E}$ (N45-60 $\mathrm{W}$ direitas), e o N-S dextral por aquelas $\mathrm{N} 0-30^{\circ} \mathrm{E}$ a N0-15 $\mathrm{W}$ (E-W esquerdas), que deslocam falha normal NE-SW localizada (Fig. $8 \mathrm{H}$ ). Conjunto menor de estruturas dextrais NE-SW sobreposto pelas sinistrais é também observado.

\section{Regimes cinemáticos}

- Sistema transtensivo sinistral do final do Ediacarano ( $\leq 565$ - $570 \mathrm{Ma}$ ): NE-SW a NNE-SSW, com máxima compressão N-S (Fig. 9A), representado pela reativação da Z. F. Cerro dos Cabritos no final do Ediacarano, como aponta a relação com o granito Jaguari. O mesmo é sugerido para direçóes similares no setor norte da Formação Hilário (Fig. 9C) e para a Z. F. Cerro Alegre, que equivaleria à reativação concomitante de falhas antitéticas da transcorrência dextral prévia (Fig. 9B).

- Sistema transtensivo do Ediacarano $(\approx 590-600 \mathrm{Ma})$ : WNW-ESE a NW-SE sinistral e NE-SW dextral, com máxima compressão ENE-WSW a WNW-ESE, expresso na área de transferência da Z. F. Palma-Jacques. Compatibilidade parcial entre falhas NW-SE sinistrais, NE-SW dextrais e as normais, evidenciada pelos eixos $\mathrm{P}$ (Figs. 9D a 9F), sugere fases alternadas do mesmo evento tectônico. O stock de QMP sinaliza a idade deste evento dado que, ao contrário da sequência vulcânica, registra apenas as fases a ele vinculadas.

- Sistemas transcorrentes dextrais do início do Ediacarano ( $\leq 620$ - $630 \mathrm{Ma}$ e > $600 \mathrm{Ma})$ : WNW-ESE a ENE-WSW e NW-SE (NE-SW sinistral), registrados nos setores das formaçôes Hilário e Maricá ao sul, e, talvez, no embasamento sudeste. Os dois sistemas correspondem a fases tectônicas sucessivas com máxima compressão variando de N-S a NW-SE (Figs. 9G e 9H). Aquele NW-SE seria o mais antigo na base da Bacia do Camaquá, de modo que pequenas oscilaçóes nas tensóes crustais teriam ativado estruturas E-W pré-existentes. Este aparenta ser o evento tectônico mais abrangente, responsável pela formação das zonas de falha Passo das Carretas, Cerro dos Cabritos e Palma-Jacques.

\section{GRANITO LAVRAS}

\section{Magnetometria}

Importante baixo magnético no centro do granito Lavras (-115 nT), alinhado segundo NE-SW (Fig. 10A), corrobora estrutura rúptil profunda. Este baixo deve também refletir diferenças composicionais realçadas pela suscetibilidade magnética (Fig. 13E), que tende a crescer dos termos magnesianos centrais $\left(<8^{*} 10^{-3} \mathrm{SI}\right)$ para os ferrosos da borda $\left(8-16^{*} 10^{-3} \mathrm{SI}\right)$. Nos mapas GHT-RTP continuados, sobressai o alto magnético circular sob o monzogranito, que é mais largo e de maior amplitude em profundidade (Fig. 6C). Em níveis sucessivamente mais rasos, este é interrompido e deslocado por falhas dextrais NE-SW no noroeste (Fig. 10C), tornando-se a seguir fino e segmentado 


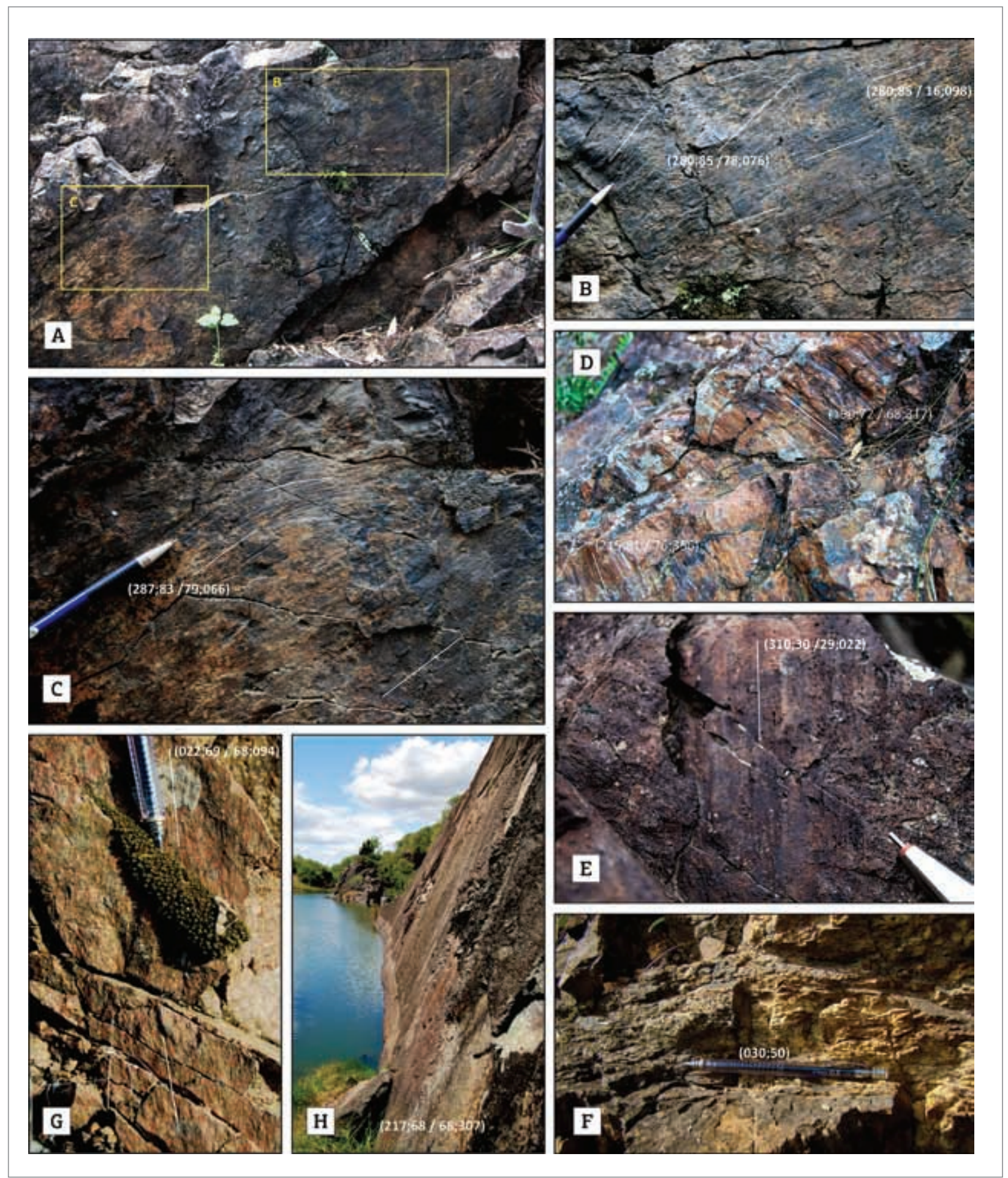

Figura 8. Fotografias de estruturas frágeis regionais (pontos na Fig. 7A, atitude $c f$. regra da mão esquerda): (AC) Plano de falha WNW-ESE com superposição de estrias, em lápili-tufo (pt. 15-oeste). Estrias com caimento moderado e sentido direito (B), encurvadas e sobrepostas pelas subverticais com sentido normal (C); (D) Planos estriados $\mathrm{N} 10-35^{\circ} \mathrm{E} / \mathrm{NW}$ com alto caimento, em lápili-tufo (pt. 16-sudeste; largura da foto = 0,6 m); (E) Plano discreto de falha normal NW-SE de baixo ângulo, secionando veios finos de quartzo $\mathrm{N} 25^{\circ} \mathrm{W} / \mathrm{SW}$, em ignimbrito (pt. 18); (F) Zona de cataclase estreita $(15-20 \mathrm{~cm})$, com microfraturas abundantes, em quartzo monzonito porfirítico (QMP; pt. 23-norte); (G) Plano estriado em falha normal no sul do QMP (pt. 24-norte); e (H) Plano de falha normal NE-SW, em tufo (pt. 30-norte). 
(Fig. 10B). Enclaves microgranulares máficos distribuídos ao longo e na porção externa sugerem algum tipo de estrutura circular profunda, vinculada à alimentação de magmas máficos (Fig. 10C). Lineamentos magnéticos N60-70 E a
$\mathrm{N} 40-50^{\circ} \mathrm{E}$ são expressivos no centro, ocupado pelo granodiorito (Figs. 10 e 11A). Estes são interrompidos no sul por aqueles ENE-WSW a WNW-ESE, que condicionam os granitos da borda. Para norte predominam lineamentos

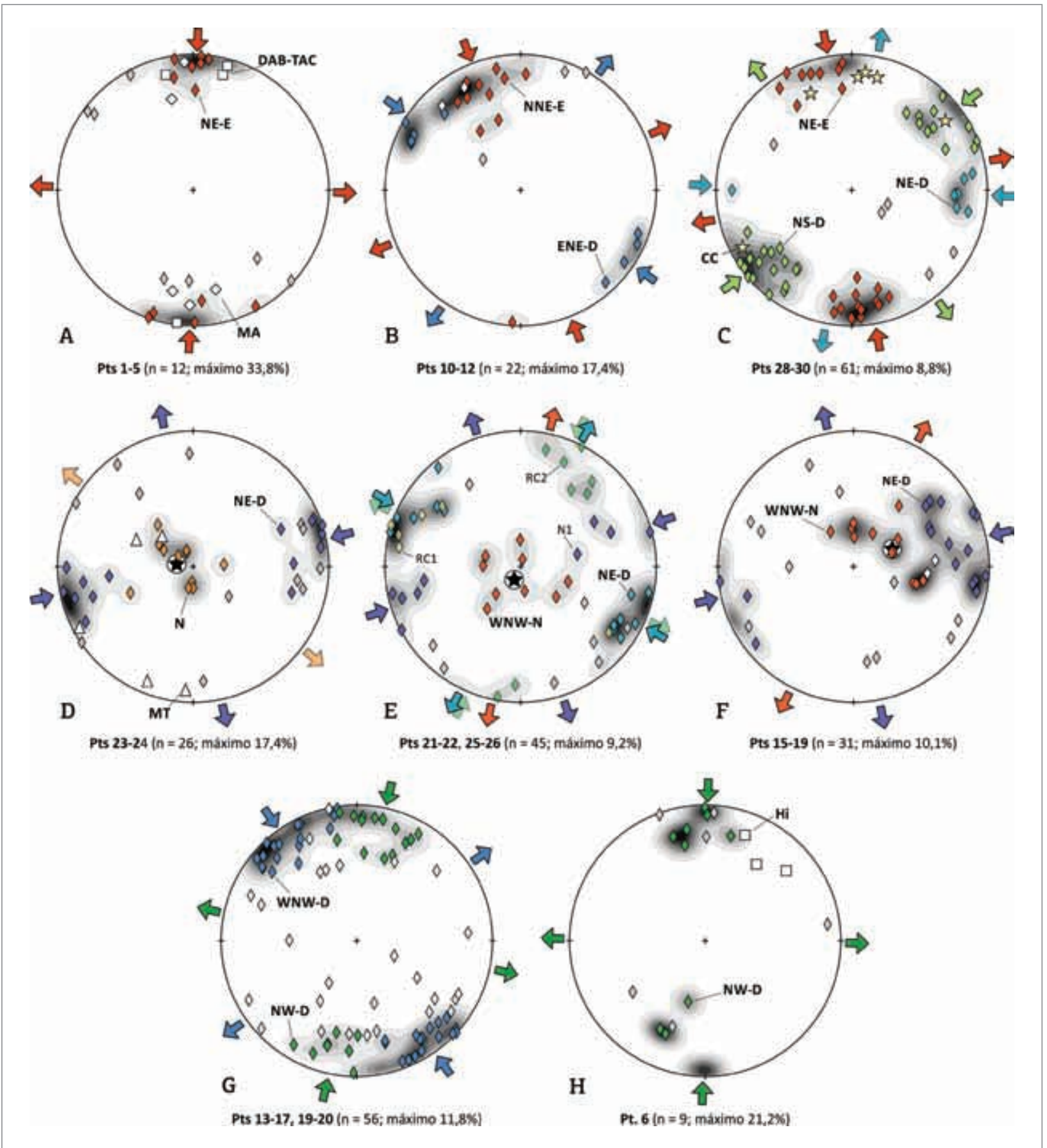

Figura 9. Estereogramas exibindo o contorno e os eixos $\mathrm{P}$ (contração) para as populações de falhas consideradas (Rede de Schmidt, hemisfério inferior; contornos e pontos seguem Fig. 7), e a direção dos componentes de máximo e mínimo stress. Losangos coloridos para falhas consistentes com a solução, cinza para as não consistentes e branco para aquelas que satisfazem mais de uma solução. São mostradas as falhas não consideradas nas soluções no embasamento e Formação Maricá (A) (DAB-TAC, pts. 34-35 e 32), na cobertura sedimentara leste (C) (CC, pts. 24 e 27), no monzonito (D) (MT, pt. 33), e no setor sul da Formação Hilário (H) (Hi, pts. 7-9). 
de direção WNW-ESE a N60-75 W, enquanto aqueles NNE-SSW controlam os limites leste e oeste do pluton.

\section{Estruturas rúpteis}

Falhas de mergulho alto a moderado, WNW-ESE a NW-SE sinistrais e NE-SW dextrais, exibem feições similares às regionais (Figs. 11 e 12) e são correlacionadas ao sistema transtensivo sinistral da Z. F. Palma-Jacques (Figs. 9D a $9 \mathrm{~F}$ ). Estruturas com deslocamento contrário são localizadas no monzogranito central e sienogranito intermediário e muito escassas no granodiorito seriado (Figs. 11B e 11C). Estas são interrompidas ou deslocadas por aquelas dextrais NE-SW, e todas interceptadas pelas sinistrais WNW-ESE a NW-SE. No monzogranito e sienogranito intermediário,

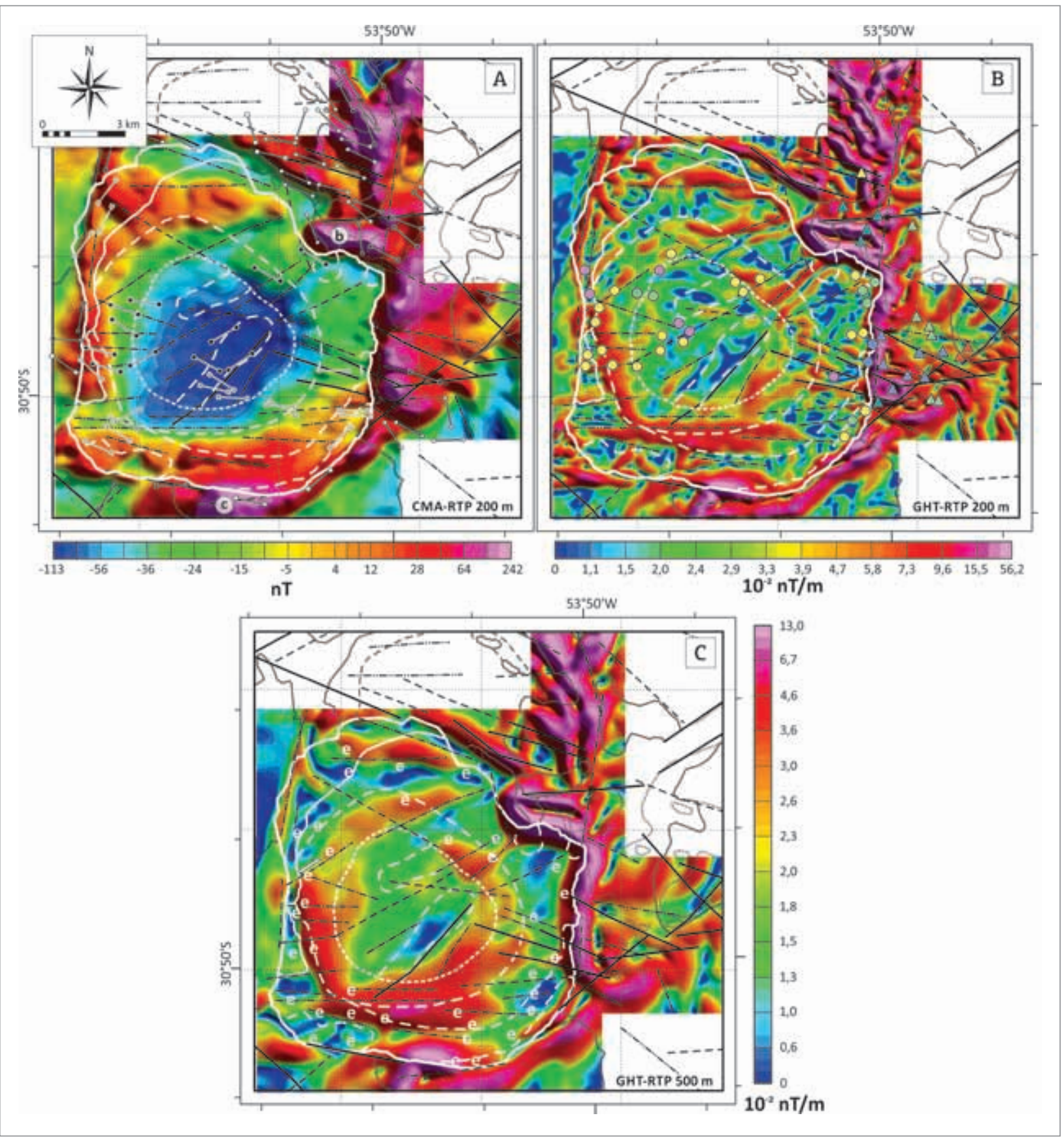

Figura 10. Mapas magnéticos do granito Lavras (Amarillo 2007), calculados com base nos dados do campo magnético anômalo reduzido ao polo (coordenadas e contatos seguem Fig. 2A: (A) Campo magnético anômalo continuado 200 m; (B e C) Gradiente horizontal total continuado 200 e 500 m, respectivamente. São mostrados diques (A) e ocorrências de metais (B), conforme Fig. 3A; afloramentos com enclaves microgranulares (C) (Fig. 2A); anomalias magnéticas (A) (Fig. 6B). Lineamentos como na Fig. 6, acrescidos daqueles detalhados nestes mapas (linha tracejada-pontilhada). 
falhas dextrais $\mathrm{N} 50-70^{\circ} \mathrm{E}$ a $\mathrm{N} 80-85^{\circ} \mathrm{E}$ na porção norte do pluton são associadas às normais com mergulho para noroeste ou sudeste (pts. 5-6 e 16-17 - Figs. 11A e 11B), enquanto as antitéticas $\mathrm{N} 10-30^{\circ} \mathrm{W}$ predominam no leste. No granodiorito predominam falhas dextrais $\mathrm{N} 45-60^{\circ} \mathrm{E}$ a N $70-75^{\circ} \mathrm{E}$ (Figs. 11C e 12B e 12C), e as antitéticas são mais variadas, algumas com deslocamento normal ou reverso. A população WNW-ESE sinistral, nos termos magnesianos, inclui as direçōes $\mathrm{N} 70-90^{\circ} \mathrm{W}$ a N45-60 $\mathrm{W}$ (Fig. 12A). Estruturas subsidiárias dextrais $\mathrm{N} 05-15^{\circ} \mathrm{E}$ a $\mathrm{N} 25-35^{\circ} \mathrm{E}$ sáo comuns, todavia no oeste (pt. 2) formam zonas de fraturamento cerrado com escassos indicadores cinemáticos.

A população mais jovem, dominante nos granitos da borda (Fig. 11D), inclui direçóes variadas de $\mathrm{N} 75-85^{\circ} \mathrm{W}$ a N35- $40^{\circ} \mathrm{W}$ e $\mathrm{N} 85-90^{\circ} \mathrm{E}$, além das antitéticas N-S em zonas amplas de fraturas densas no leste (Fig. 12D). Falhas NNW-SSE sinistrais e zonas de cataclase N30-50 $\mathrm{E}$ a $\mathrm{N} 65-75^{\circ} \mathrm{E}$ são subordinadas. Na cava Boa Vista (Fig. 11E), sobressaem as direçôes WNW-ESE a N40-50 $0^{\circ} \mathrm{W}$ sinistrais e as antitéticas NNE-SSW, ambas em zonas de fraturamento mais intenso (5-10 $\mathrm{m}$ de largura), em cuja interseçâo estão as áreas hidrotermalizadas. Naquelas NNE-SSW dextrais, intensa cataclase com padrão anastomosado e falhas reversas sugerem sítios transpressivos (Fig. 12E). Interação entre segmentos enéchelon de dique máfico referenda atividade ígnea durante esta fase tectônica (Fig. 12F).

\section{Gravimetria}

O mapa de anomalias Bouguer mostra o pluton associado a uma depressão assimétrica (Fig. 13A), com anomalias negativas no oeste-noroeste $(-14,3$ a $-23,1 \mathrm{mGal})$ e positivas no sudeste-leste ( 8 a $2 \mathrm{mGal}$ ). A densidade de $2.620 \mathrm{~kg} / \mathrm{m}^{3}$ equivale à média dos valores, entre $2.643 \mathrm{~kg} / \mathrm{m}^{3}$ no monzogranito e $2.578 \mathrm{~kg} / \mathrm{m}^{3}$ no feldspato alcalino granito, ponderada pela área. Essa média é inferior à densidade das rochas circundantes, com exceçấo dos granitos a oeste (GJ e GFP - Fig. 2A) e dos arenitos a sul, onde resíduos positivos confirmam corpo máfico subsuperficial. Depressão das anomalias residuais ( $<-9$ a $-19 \mathrm{mGal})$, limitada no sul por lineamentos WNW-ESE a ENE-WSW (Fig. 13B), caracteriza a porção centro-norte do granito Lavras, na qual são definidos quatro baixos circulares a elípticos, interpretados como raízes alimentadoras (I a IV - Fig. 13C). Em face da assimetria das anomalias, o contorno do granito não corresponde a um único nível no mapa gravimétrico residual. Tal complexidade, agravada por lacunas na malha de medidas, dificulta o ajuste do modelo 3D (Cunha et al. 2008). O mapa de profundidades, apesar disso, é consistente com os demais dados (Fig. 13C). O assoalho é quase plano no centro-norte (profundidades de $3,4-3,0 \mathrm{~km}$ ), com quatro raízes discretas
$(0,35-0,60 \mathrm{~km})$, enquanto no sul, profundidades entre 3,0 e $1,2 \mathrm{~km}$ definem uma rampa com aclive acentuado $\left(55-70^{\circ}\right)$.

\section{Domínios composicional-estruturais}

Os dois domínios composicionais no GL são realçados por forte contraste do sinal nos mapas do eTh (Fig. 14A) e eU (náo mostrado), e por resposta irregular no do K (Fig. 14B). Os valores de eTh e eU são baixos nos dois termos centrais e elevados nos demais. O sinal diferenciado do sienogranito intermediário parece refletir sua composiçáo particular (Fig. 4), como discutido em Gastal et al. (2006). A fácies porfirítica do granodiorito, pouco destacada no mapa do eTh, forma altos no mapa do $\mathrm{K}$, alinhados segundo $\mathrm{N} 60-70^{\circ} \mathrm{E}$ no leste e irregulares no oeste.

Os estudos de magnetismo de rocha neste granito revelam que a trama ASM (anisotropia de suscetibilidade magnética) é magmática e é dada pela magnetita multidomínio (Raposo \& Gastal 2009). Lineaçóes e foliaçôes magnéticas, subparalelas aos contatos (Fig. 13D), indicam alimentaçáo de magma a partir da base com fluxo condicionado pelas margens. Estrutura dômica centrada no granodiorito é definida pelas foliaçóes, cujos mergulhos crescem deste para os termos da borda (Figs. 13D e 13F). Todavia nos últimos, os mergulhos passam a verticais e invertem para centrípetos no sul, indicando alojamento distinto. O mesmo é sugerido, no oeste-noroeste, pelo contraste acentuado no mergulho das foliaçôes entre o feldspato alcalino granito $\left(\geq 72^{\circ}\right)$ e o monzogranito $\left(\leq 32^{\circ}\right)$. As lineaçóes exibem baixo caimento $\left(\leq 22^{\circ}\right)$, exceto nos termos da borda no sudeste, onde inclinaçáo elevada $\left(\geq 53^{\circ}\right)$ é consistente com conduto de magma segundo falha periférica NE-SW. No granodiorito, as lineaçóes exibem disposiçấo algo radial, sugerindo fluxo de magma no topo da intrusão a partir do centro (Fig. 13D). Em todos, o elipsoide ASM varia de oblato a triaxial (ou neutro; Fig. 13E), e o grau de anisotropia é moderado a baixo (< 13\%). Parâmetro de forma mais elevado nos termos centrais $(T=0,4-0,7)$, com exceção de uma amostra de granodiorito porfirítico, indica deformação planar no topo do domo central, corroborando dois domínios composicional-estruturais.

\section{DISCUSSÃO}

\section{Mecanismos de alojamento do granito Lavras}

O granito Lavras é um pluton de dimensōes modestas $\left(\approx 107 \mathrm{~km}^{2}\right.$ e $\left.325 \mathrm{~km}^{3}\right)$, com forma tabular (L:E $\left.\approx 3: 1\right)$ afinando para sul sugerida pela gravimetria (Fig. 13C). O alongamento e o alinhamento das raízes alimentadoras referendam o alojamento influenciado por estruturas preexistentes, 


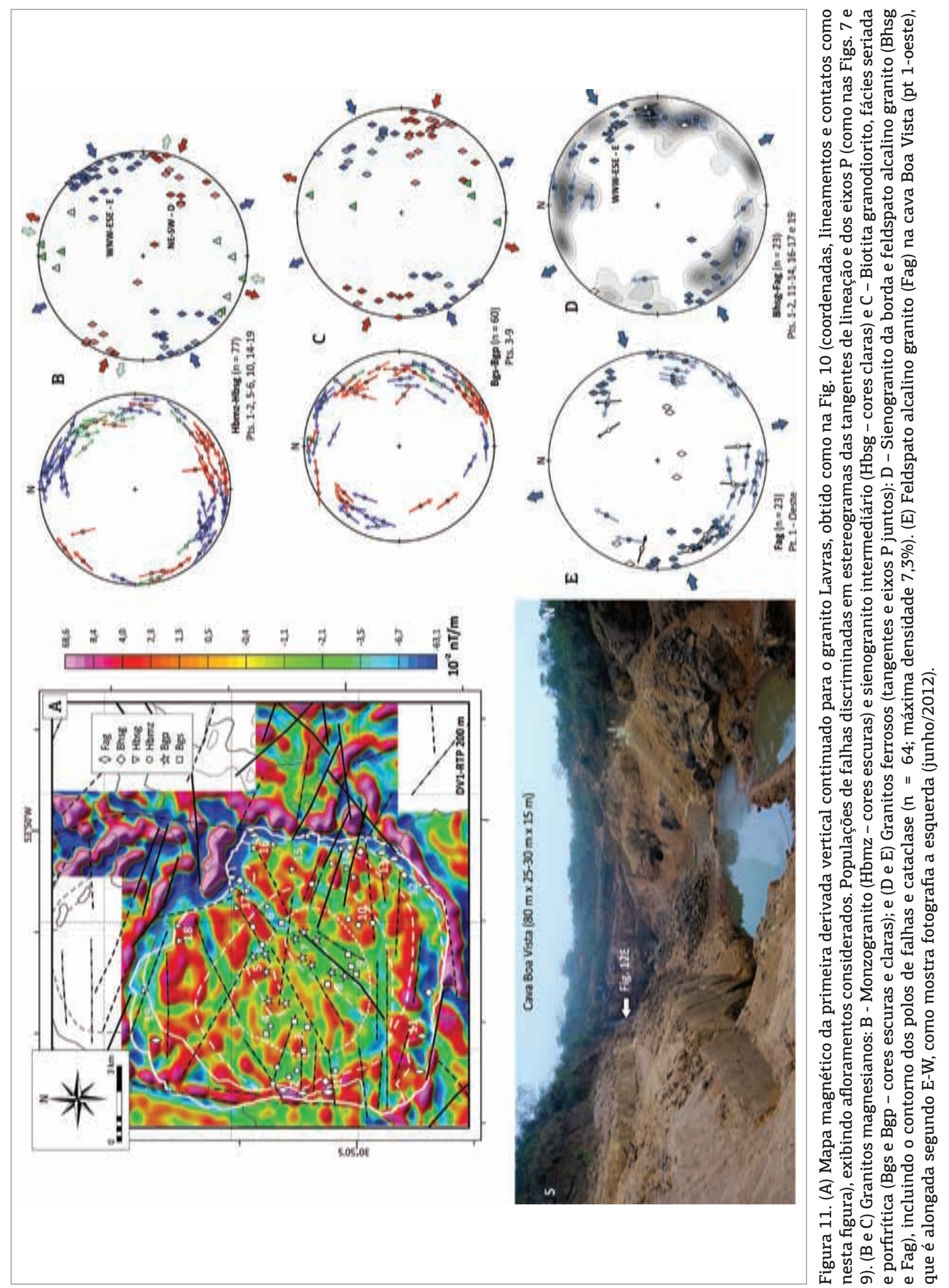


NE-SW e WNW-ESE a NW-SE (Fig. 13B). Sua natureza multicíclica é definida por dois domínios composicional-estruturais (Figs. 4, 10A, 13D a 13F e 14), com os termos magnesianos associados a corpo do tipo lacólito e os ferrosos, a intrusóes periféricas, parcialmente concordantes no norte e divergentes no sul. Nos primeiros, a trama ASM indica arqueamento de camadas ou pulsos de magma alojados a partir da base, como desenvolvimento do lacólito central (Raposo \& Gastal 2009). Isso pressupóe processos de ressurgência da câmara magmática, dado que subsidência em profundidade implica alimentação lateral a partir do topo em razão do abatimento passivo de blocos centrais (Burchardt et al. 2012). Dois pulsos de magma, pelo menos, são requeridos na formação da soleira monzogranítica e do granodiorito
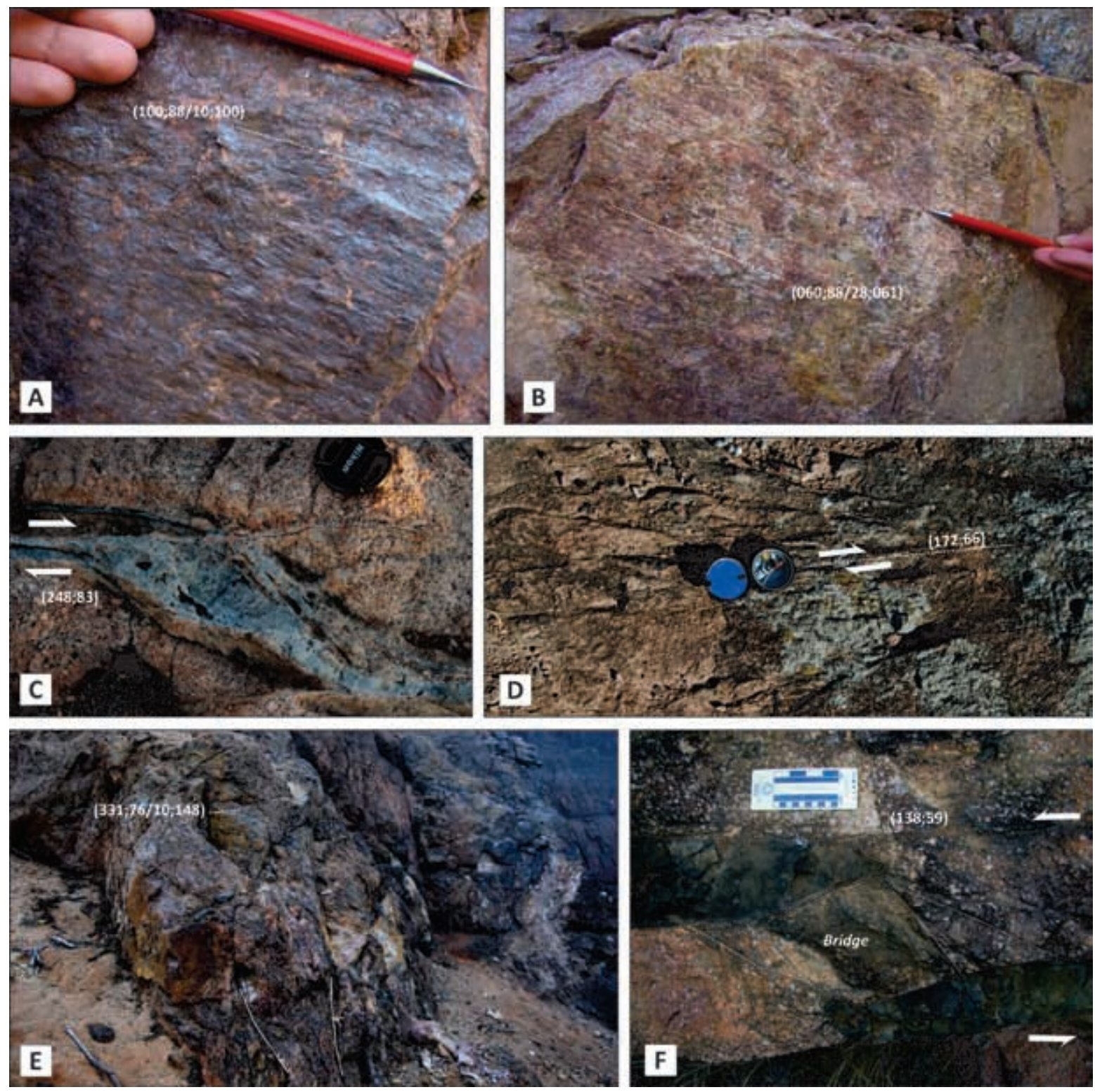

Figura 12. Fotografias de estruturas rúpteis no granito Lavras (pontos e siglas na Fig. 11A; atitude cf. regra da mão esquerda): (A) Plano de falha estriado WNW-ESE sinistral, coberto com hematita (pt. 6-norte, Hbmz); (B) Plano de falha estriado NE-SW dextral (pt. 7-sudeste, Bgp); (C) Jog transtensivo dextral, em veio de quartzo NE-SW (pt. 8-leste, Bgp); (D) Splay dextral NNW-SSE, em sistema denso de fraturas (pt. 14-oeste, Bhsg); (E) Zona de intensa cataclase NNE-SSW, interrompida por plano estriado NW-SE sinistral (bancada sul, cava Boa Vista; Fag); e (F) Interação parcial entre segmentos de dique máfico en échelon (10 - $15 \mathrm{~cm}$ de espessura; pt. 1-oeste; Fag). 


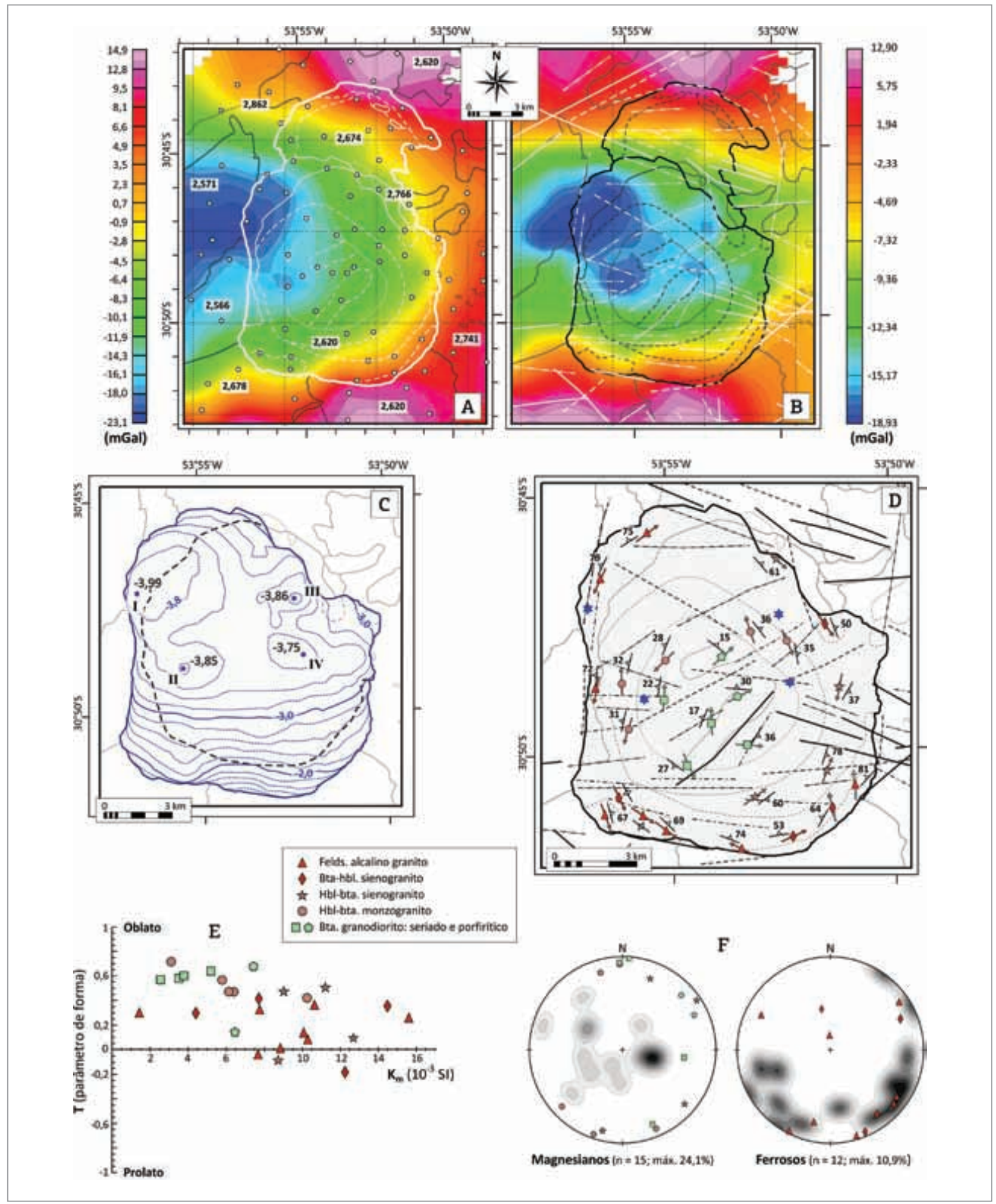

Figura 13. Granito Lavras: (A-C) Gravimetria (Cunha et al. 2008). Mapas das anomalias Bouguer (A) e residuais (B). Em A, estações de medida e valores médios de densidade $\left(e m 10^{-3} \mathrm{~kg} / \mathrm{m}^{3}\right.$ ) (contatos, lineamentos e coordenadas seguem Figs. 2A e 10); (C) Mapa das profundidades do assoalho, obtidas por inversão gravimétrica 3D (isóbatas a $0,20 \mathrm{~km}$; contraste de densidade de $-105,7 \mathrm{~kg} / \mathrm{m}^{3}$ ). Números romanos para as principais raízes; (D-F) Anisotropia de suscetibilidade magnética (ASM) (Raposo \& Gastal 2009). (D) Mapa simplificado exibindo foliação e lineação magnética. Números para mergulho da foliação e seta branca para lineação subvertical; e as quatro raízes como em C; (E) Diagrama do parâmetro de forma do elipsoide ASM - T versus o valor médio da suscetibilidade magnética $\mathrm{K}_{\mathrm{m}}$; e $(\mathrm{F})$ Estereogramas (Rede de Schmidt, hemisfério inferior) para contorno dos polos da foliação (densidade máxima conforme Fig. 2, para $\mathrm{K}=60$ ) e símbolos para lineação, nos granitos magnesianos e ferrosos. 
subjacente. Ao intrudir a soleira, o granodiorito promoveu seu arqueamento e o rompimento do teto segundo falhas NE-SW dextrais, acarretando a descompressão do magma (quenching) e a formação da fácies porfirítica do granodiorito (Fig. 2A). Entretanto, não é possível descartar o vínculo da soleira precursora com possível dique anelar (Figs. 6C,10B, 10C e 15B).

Corpos distintos de granitos ferrosos foram alojados ao longo de estruturas rúpteis periféricas, na interseção ou próximo daquelas ativadas com a formação do lacólito, como os de nordeste e noroeste (Figs. 10 e 11). No sul, o alojamento foi favorecido pela ruptura das encaixantes segundo falhas periféricas ENE-WSW e NE-SW (Figs. 13D), o que pode explicar a maior movimentação dos estratos sedimentares (Fig. 2A). Os granitos ferrosos promoveram, assim, a ampliação lateral do pluton durante máxima extensão segundo NW-SE a NNW-SSE (Figs. 11D e 11E), o que requer expansão da câmara magmática sotoposta (Fig. 15D). Portanto, não representam diques ou intrusóes anelares, dado que a definição original de tais termos inclui critérios descritivos e genéticos, específicos do momento da subsidência (Roberts 1970; Stevenson et al. 2008). Sua geometria é consistente com episódios finais na câmara magmática, quando intrusôes anulares ressurgentes reativam falhas periféricas ou antigos diques anelares (Johnson et al. 2002; Saunders 2005;
Kennedy \& Stix 2007). O crescimento dessas intrusóes, em incrementos de magma, envolve mecanismos do tipo crack-seal que dependem das condições de extensão, da pressão do magma e do restabelecimento do comportamento reológico favorável à fratura a cada incremento (Bartley et al. 2008). Isso implica crescimento lento das intrusóes anulares no GL, explicando contatos bruscos sem a redução da granulação por causa do contraste termal. A expansão da câmara sotoposta pode ser atribuída à recarga com magma hidratado de alta temperatura, análogo aos diques máfico-ultramáficos lamprofíricos (Fig. 3), o que justifica a composição distinta dos granitos (Fig. 4).

\section{Tectônica rúptil e o centro vulcano-plutônico}

Os dois eventos tectônicos com cinemática contrária e direção NW-SE a WNW-ESSE foram determinantes no posicionamento e na evolução do centro vulcano-plutônico. O sistema transcorrente NW-SE dextral $(<620-630 \mathrm{Ma}$ e > $600 \mathrm{Ma}$ ) corresponde aos eventos finais da Orogênese Dom Feliciano (<620 - 640 Ma) no antepaís. A fase tardia WNW-ESE dextral, respondendo a menor stress diferencial próximo ao colapso desta, teria favorecido o início da atividade vulcânica $(\approx 600-610 \mathrm{Ma})$. O sistema WNW-ESE transtensivo sinistral $(\approx 590-600 \mathrm{Ma})$, restrito à Z. F.

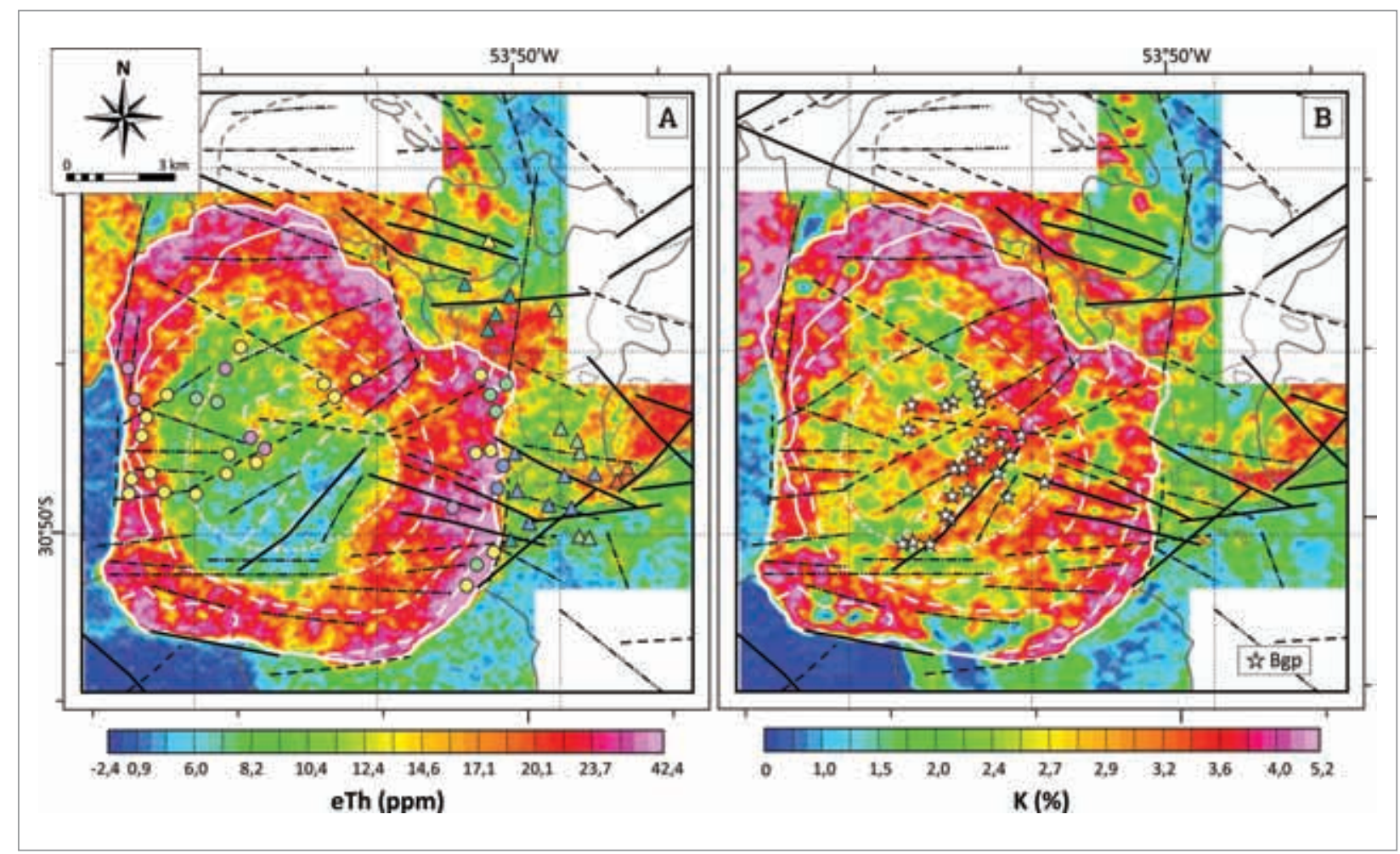

Figura 14. Mapas gamaespectrométricos do granito Lavras (Amarillo 2007): (A) e Th (ppm) e (B) K (\%). Prospectos de $\mathrm{Au}-\mathrm{Cu}-\mathrm{Pb}(\mathrm{Ag})$ em A (Fig. 3A), e afloramentos da fácies porfirítica do granodiorito em $\mathrm{B}$ (Bgp). Contatos, lineamentos e coordenadas seguem Figs. $2 \mathrm{~A}$ e 10. 


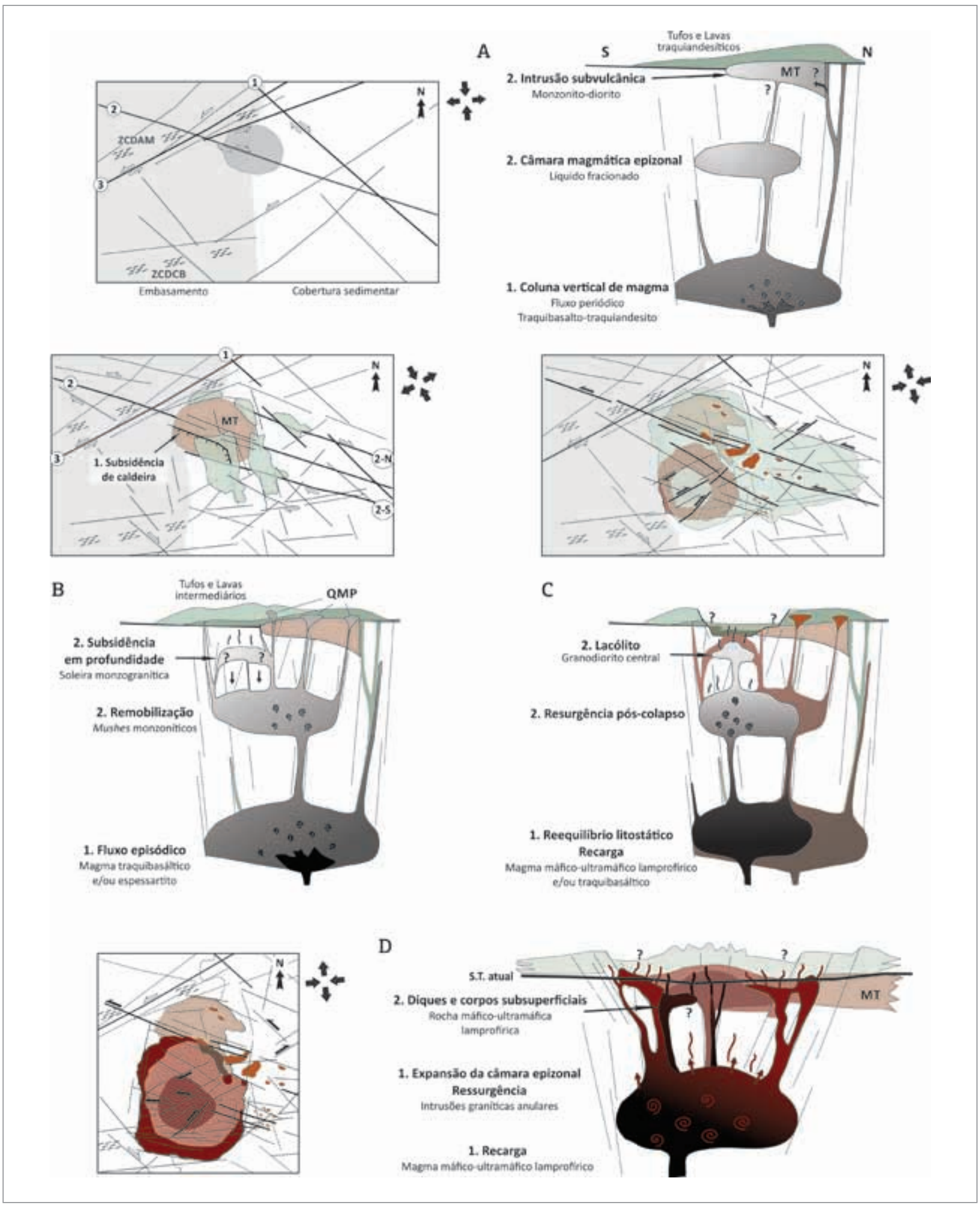

Figura 15. Cartoons ilustrando estágios na construção do centro vulcano-plutônico durante a mudança no deslocamento da Z. F. Palma-Jacques, de dextral (A e B) para sinistral (C e D). São indicados os componentes de máximo e mínimo stress, a atividade magmática e estruturas rúpteis em mapa esquemático (linhas contínuas para falhas ativas - preta e pré-existentes ou inexpressivas - cinza; feições seguem Figs. 2A, 6, 9 e 11), e na coluna vertical de magma ( $\approx \mathrm{N}-\mathrm{S}$, sem escala): (A) Estabelecimento da coluna vertical de magma traquibasáltico; (B) Remobilização de mushes cristalinos na câmara epizonal, seguida por episódios de subsidência de caldeiras em superfície e em profundidade; (C) Restabelecimento do equilíbrio litostático com o ascenso de magmas a partir de níveis mais profundos, ocasionando a ressurgência central; e (D) Ressurgência via intrusões anulares graníticas induzidas por magma máfico-ultramáfico lamprofírico no nível epizonal. 
Palma-Jacques (ZFPJ), marca a inversão nas condiçóes de stress regional atribuído ao relaxamento tectônico, comum em orogenias oblíquas. A ZFPJ corresponde a lineamento longo e difuso (Figs. 5 e 7A), sendo difícil interpretá-la como uma descontinuidade litosférica, em analogia a outros locais em que a atividade ígnea e a movimentação destas estruturas são coevas (Acocella \& Funiciello 2010; Pirajno 2010).

Em ambiente pós-colisional distante do front colisional, contudo, as zonas de transtensáo apresentam atividade irregular e cinemática difusa (Shabanian et al. 2012). Este parece ser o caso da ZFPJ, cuja movimentação foi coeva à atividade magmática. Seus segmentos condicionam os limites do monzonito Tapera (MT), sugerindo o papel do reservatório magmático na partição da deformação (Figs. 6 e 15B). Estes segmentos atuaram como condutos para magmas diversos, traquiandesíticos no norte e também quartzo monzoníticos no sul (Fig. 3A). Além disso, diques ao longo da ZFPJ sugerem atividade magmática paralela à ruptura do MT durante episódio de subsidência de caldeira, consistente com tectônica transtensiva. Nesse caso, a falha mestra acima do reservatório magmático acomoda estruturas extensivas durante o deslocamento lateral, porém não é ativada com a subsidência (Holohan et al. 2008). Atua como barreira à propagação de falhas subsidiárias que condicionam o colapso, de modo que o limite da área abatida é irregular e escalonado, como no sudeste do MT (Fig. 2A).

A inversão no deslocamento das estruturas rúpteis é evidente na sequência vulcânica, porém apenas o evento tardio está registrado no stock de QMP e granito Lavras (Figs. 7, 9 e 11). A interseção das zonas de falha Palma-Jacques e Passo das Carretas seria suficiente para ocasionar intenso fraturamento a leste (Fig. 5B), todavia a geometria e a sucessão de falhas na zona de transferência da ZFPJ corroboram duplex transtensivo esquerdo (Fig. 6). A alternância entre fases tectônicas de direção WNW-ESE sinistral e NE-SW dextral, com movimento lateral e normal na sequência vulcânica e lateral no granito, é consistente com esse tipo de estrutura duplex (Dooley \& Schreurs 2012). As últimas (NE-SW), em alto ângulo com o deslocamento principal, teriam sido ativadas pela rotação local dos tensores de stress em face da construção do centro vulcano-plutônico (Fig. 11), paralela à migração para sul das zonas de extensão (Fig. 15C). O granito, então, é construído na interseção da falha NE-SW com o segmento sul da ZFPJ. A mudança na composição dos diques WNW-ESE a ENE-WSW acompanha esta migração (Fig. 3A).

Apesar da equivalência entre eventos tectônicos e ígneos, levantamentos futuros são requeridos para detalhar o efeito da saturação em fraturas em terrenos antigos e as reativações posteriores. A inversão no regime tectônico, contudo, é a alternativa adequada para explicar magmas máfico-ultramáficos lamprofíricos no final da evolução do centro vulcano-plutônico e sua relação com a ZFPJ. Tal inversão é suficiente para que o manto litosférico metassomatizado, em condição próxima à solidus, entre em regime de fusão parcial por descompressão. Segundo Vaughan e Scarrow (2003), este processo é também capaz de induzir a reativação de zonas transtensivas difusas em ambiente pós-colisional. $\mathrm{O}$ intervalo de c.a. 30 m.a., entre o término desses eventos ígneos em Lavras $(\approx 590 \mathrm{Ma})$ e o clímax colisional Dom Feliciano (620 - 640 Ma), é condizente ao descrito em contexto similar por Prelevic et al. (2005).

\section{Considerações sobre a mineralização}

Estruturas rúpteis ativadas durante regime sinistral da ZFPJ constituem o principal controle da mineralização no distrito aurífero de Lavras do Sul (Figs. 3A, 10A e 14A). As ocorrências não mostram correlação clara com a zonação dos granitos, estando distribuídas próximas ou na interseção de falhas WNW-ESE ( \pm NW-SE) com as NE-SW e NNE-SSW. O papel exercido por essas estruturas durante o alojamento das intrusóes anulares sugere que elas sejam reflexo do comportamento das rochas encaixantes diante da expansão do reservatório magmático sotoposto. Granitoides mais resistentes no oeste induziram a reativação de estruturas rúpteis no interior do pluton, enquanto no leste, as rochas vulcânicas estavam intensamente fraturadas em razão do desenvolvimento do duplex transtensivo sinistral e do centro vulcano-plutônico. Consequentemente, os prospectos são frequentes na metade oeste e restritos ao contato no leste (Fig. 3A). Isso fortalece o vínculo da mineralização com os últimos episódios de ressurgência, ocasionados por magmas máfico-ultramáficos lamprofíricos. As intrusôes anulares decorrentes, formadas em pequenos incrementos, seriam capazes de reter fluidos e magma no nível epizonal $(\geq 4 \mathrm{~km}$ ), requisito-chave para depósitos do tipo pórfiro (Sillitoe 2010; Kennedy et al. 2012).

A gênese das ocorrências neste distrito, entretanto, não está vinculada diretamente aos granitos como argumentam Remus et al. (2000) e Bongiolo (2006), ao contrário do que ocorre nos depósitos clássicos do tipo pórfiro (Sillitoe 2010). No caso de depósitos do tipo $\mathrm{Cu}-\mathrm{Au}$ pórfiro e Au-epitermal em posiçôes isoladas nos arcos continentais e em ambientes pós-colisionais, a mineralização cuprífera está associada a magmas intermediários e a aurífera àqueles máficos lamprofíricos tardios (Richards 2009). Tal alternativa seria capaz de explicar a zonalidade no distrito de Lavras do Sul, Au versus $\mathrm{Cu}-\mathrm{Pb}$ (Fig. 3A), bem como paragêneses do minério distintas em rochas vulcanogênicas dos dois distritos, Lavras do Sul (Cu-Au) e Seival $(\mathrm{Cu})$. Em Lavras, essas rochas ficaram expostas à atividade hidrotermal prolongada, sujeitas à superposição de diferentes episódios mineralizadores. 


\section{Modelo integrado}

O modelo esboçado considera a coluna vertical de magma (Mush column; Marsh 2000), estabelecida durante regime dextral da Z. F. Palma-Jacques. A diversidade de magmas nessa coluna depende da frequência na atividade magmática, que é reduzida no período pós-colisional $(1-5 \mathrm{Ma})$. O estágio inicial (Fig. 15A), com fluxo periódico de magma traquibasáltico a traquiandesítico, traduz a formação do reservatório precursor alojado em interface entre o embasamento e a cobertura sedimentar (Formação Maricá), na interseção das zonas de falha Palma-Jacques (WNW-ESE dextral) e Cerro dos Cabritos (NE-SW sinistral). O monzonito Tapera (MT) equivale à intrusão subvulcânica, talvez alimentada por conduto lateral durante a expansão deste reservatório (anomalia “a” - Fig. 6B).

A crescente descompressão, próxima ao final do período pós-colisional, propicia a diversificação na produção de magmas no manto a partir de fontes mais profundas metassomatizadas, provendo magmas lamprofíricos ao sistema. Magmas hidratados como esses, ao reativarem a coluna vertical, vesiculam no nível epizonal ( $\leq 400 \mathrm{MPa}$ ) (Edmonds 2010), acarretando grande expansão do reservatório. Embora mais esparsas, as recargas ocasionam períodos muito dinâmicos, com ciclos sucessivos de subsidência-ressurgência em superfície e em profundidade. No segundo estágio (Fig. 15B), fluxo mais esparso ao longo da coluna, incluindo também magma espessartítico, seria responsável pelo alojamento de corpos máficos (anomalias "b" e "c" Fig. 6B) e pela reativação de mushes cristalinos monzoníticos no nível epizonal, com a geraçáo de líquidos quartzo monzonitos. Esses líquidos magmáticos foram alojados em inúmeros corpos subvulcânicos (QMP - Figs. 2A e 4A) em razão da evasão lateral facilitada pelo intenso fraturamento a leste. Tal processo de evasão sela as estruturas rúpteis ao redor e ocasiona deflação na câmara magmática, favorecendo subsidência em profundidade, que poderia ser associada à soleira monzogranítica. A ruptura e o colapso parcial do MT teriam ocorrido durante um ou mais episódios de subsidência, aparentemente, anteriores e mais superficiais.

A resposta crustal ao desequilíbrio litostático, gerado com o colapso de caldeira, envolve o ascenso de magma de níveis mais profundos, que remobiliza e interage com o líquido residual na câmara, ocasionando a ressurgência. Isso intensifica o fraturamento do teto, facilitando a intrusão e erupção de parcelas de magma, o desenvolvimento de amplo sistema magmático-hidrotermal e sua interação com fluidos meteóricos. Intrusôes centrais, na forma de lacólito ou domo estrutural, acarretam deslocamento vertical expressivo (hm-km) em centros vulcano-plutônicos maduros (Smith \& Bailey 1968; Kennedy et al. 2012), encerrando o ciclo do edifício vulcânico (Delcamp et al. 2012).
Intrusões anulares promovem ressurgência prolongada, embora em menor escala por causa do volume reduzido de líquido residual (Saunders 2001). O terceiro estágio ilustra a ressurgência na câmara epizonal durante período de maior dinamismo do sistema, quando é estabelecida a estrutura vulcano-plutônica central (Fig. 15C). A formação do lacólito no granito Lavras ocorre após a mudança no regime tectônico, dado que a intrusão do granodiorito acompanhou o deslocamento dextral de estruturas NE-SW. Isso permite supor a entrada de magmas máfico-ultramáficos lamprofíricos em níveis mais profundos.

$\mathrm{O}$ último estágio esquematiza os eventos finais em um centro ígneo em declínio e mais frio (Fig. 15D), quando a ressurgência foi induzida pela presença destes magmas lamprofíricos de alta temperatura no nível epizonal. Disso resultaram as intrusóes anulares e a intensa atividade geotermal e hidrotermal, responsável pela mineralização aurífera. Como consequência, magmas graníticos e fluidos teriam interagido com o lacólito central via processo do tipo filter-pressing, justificando a geoquímica peculiar do sienogranito intermediário (Figs. 4 e 14). O complexo intrusivo, de acordo com o proposto, está conectado à câmara magmática epizonal com atividade prolongada submetida a sucessivas reativaçóes, o que pode ser a causa do amplo intervalo nas idades $\mathrm{U}-\mathrm{Pb}$, $\mathrm{Pb}-\mathrm{Pb}$ e $\mathrm{Ar}-\mathrm{Ar}(604$ - $586 \mathrm{Ma})$. Isso, aliado ao rejuvenescimento de sistemas isotópicos em razão da intensa atividade geotermal e hidrotermal, poderia ser aventado para explicar diferenças nas idades, em parte contrastantes, entre intrusivas e vulcânicas.

\section{CONCLUSÕES}

O modelo do centro vulcano-plutônico, que inclui o complexo intrusivo Lavras do Sul e a sequência vulcânica coeva, fornece uma alternativa aos eventos tectono-magmáticos pós-colisionais no oeste do escudo $(\approx 610-590 \mathrm{Ma})$, com implicaçôes relevantes à geodinâmica, petrogênese e metalogenia. Realça a importância de levantamentos integrados estruturais, geofísicos e geológicos no entendimento de intrusôes epizonais nestes centros ígneos. Por fim, estabelece as bases para que dados petrográficos, geoquímicos, isotópicos e geocronológicos sejam mais bem equacionados na investigação de processos e mecanismos de diferenciação magmática. A análise de estruturas rúpteis e lineamentos magnéticos aponta que a construção do centro ocorreu durante a inversão no regime de stress regional ao longo da Z. F. Palma-Jacques $\left(\mathrm{N} 70-75^{\circ} \mathrm{W}\right)$, acompanhada pela migração das zonas de extensão para sul e, ao final, pela entrada de magmas máfico-ultramáficos lamprofíricos. Falhas ativadas durante a construção do granito Lavras, que equivale ao pluton ressurgente central posicionado no sul 
do complexo intrusivo, representam o principal controle das estruturas mineralizadas. Isso, aliado à associação comum com diques lamprofíricos, corrobora o vínculo da mineralização aurífera com o último episódio de ressurgência em um centro vulcano-plutônico maduro.

\section{AGRADECIMENTOS}

Manifestamos nossos agradecimentos ao Prof. Carlos Eduardo Mesquita de Barros cujas sugestôes e comentários contribuíram à elaboração das ideias expostas, aos revisores anônimos e editores da revista e aos bolsistas de IC Laércio Dal Omo Barbosa, Melissa Abrão Zeni e Pedro Henrique Sulzbach de Andrade. Agradecemos à Companhia de Pesquisas e Recursos Minerais, CPRM - Serviço Geológico do Brasil, que cedeu os dados aerogeofísicos regionais, e à Amarillo Mineração do Brasil Ltda. que forneceu os dados geofísicos de detalhe e financiou parcialmente este trabalho. Contamos com recursos oriundos dos auxílios $\mathrm{CNPq}$ no 475388/2008-9, PRONEX/FAPERGS no 10/0045-6 e FAPERGS n ${ }^{\circ} 12 / 1980-3$.

\section{REFERENCES}

Acocella V. \& Funiciello F. 2011. Structural control of arc volcanism and related kinematic setting: An overview. Earth and Planetary Science Letters, 289:43-53.

Allmendinger R.W., Cardozo N.C., Fisher D. 2012. Structural Geology Algorithms: Vectors \& Tensors. Cambridge, Cambridge University Press, $289 \mathrm{p}$.

Angelier J. \& Mechler P. 1977. Sur une méthode graphique de recherche des constraintes principales égalment utilisable en tectonique et en séismologie: La méthode des dièdres droits. Bulletin de Société Géologique de France, 19:1309-1318.

Bartley J.M., Coleman D.S., Glazner A.F. 2008. Incremental pluton emplacement by magmatic crack-seal. Transactions of the Royal Society of Edinburgh: Earth Sciences, 97:383-396.

Bica M.M., Chemale Jr., Jelinek A.R., Oliveira C.H.E., Guadagnin F., Armstrong R. 2013. Tectonic evolution and provenance of the Santa Bárbara Group, Camaquã Mines region, Rio Grande do Sul, Brazil. Journal of South American Earth Sciences, 48:173-192.

Bongiolo E.M. 2006. Integração de dados mineralógicos, isótopos estáveis $(\mathrm{O}, \mathrm{H})$ e porosidade de rochas $\left({ }^{14} \mathrm{C}-\mathrm{PMMA}\right)$ no reconhecimento da evolução da alteração no sistema hidrotermal de Lavras do Sul/RS, Brasil. PhD Thesis, Instituto de Geociências, Universidade Federal do Rio Grande do Sul, Rio Grande do Sul, 188p.

Borba A.W., Mizusaki A.M.P., Santos J.O.S., McNaughton N.J., Onoe A.T., Hartmann L.A. 2008. U-Pb zircon and ${ }^{40} \mathrm{Ar}-{ }^{39} \mathrm{Ar} \mathrm{K}$-feldspar dating of syn-sedimentary volcanism of the Neoproterozoic Maricá Formation: constraining the age of foreland basin inception and inversion in the Camaquã Basin of southern Brazil. Basin Research, v. 20, n. 3, p. 359-375.

Burchardt S., Tanner D., Krumbholz M. 2012. The Slaufrudalur pluton, southeast Iceland - An example of shallow magma emplacement by coupled cauldron subsidence and magmatic stoping. Geological Society of America Bulletin, 124:213-227.

Catalano S., Tortorici L., Viccaro M. 2014. Regional tectonic control on large size explosive eruptions: Insights into the Green Tuff ignimbrite unit of Pantelleria. Journal of Geodynamics, 73:23-33.

Cordell L. \& Henderson R.G. 1968. Iterative three-dimensional solution of gravity anomaly data using a digital computer. Geophysics, 33(4):596-601

Cordell L. \& Grauch V.J.S. 1985. Mapping basement magnetization zones from aeromagnetic data in the San Juan Basin, New Mexico. In: Hinze W.J. (ed.). The utility of regional gravity and magnetic anomalies maps.Oklahoma, Society of Exploration Geophysicists, v. 16, p. 181-197.

CPRM. 2007. Mapa Geológico do Estado do Rio Grande do Sul. Porto Alegre, Projeto Geologia do Brasil ao Milionésimo - Programa Geologia do Brasil, CPRM - Serviço Geológico do Brasil.

CPRM. 2010. Projeto Aerogeofísico Escudo do Rio Grande do Sul. Rio de Janeiro, Programa Geologia do Brasil (PGB), Relatório Técnico da Lasa Prospecções Ltda, CPRM - Serviço Geológico do Brasil, 260p.

Cruden A.R. \& McCaffrey K.J.W. 2001. Growth of plutons by floor subsidence: Implications for rates of emplacement, intrusion spacing and melt-extraction mechanisms. Physics and Chemistry of the Earth, Part A, 26:303-315.

Cunha J.U., Ferreira F.J.F., Gastal M.C., Magro F.H.S. 2008. Modelo gravimétrico 3D do pluton granítico principal, Complexo Intrusivo Lavras do Sul - RS. In: 4o Simpósio de Vulcanismo e Ambientes Associados. Foz do Iguaçu, Resumos Extendidos (CD-Room), 5p.

Delcamp A, van Wyk de Vries B., James M.R., Gailler L.S., Lebas E. 2012. Relationships between volcano gravitational spreading and magma intrusion. Bulletin of Volcanology, 74:743-765.

Dooley T.P. \& Schreurs G. 2012. Analogue modelling of intraplate strike-slip tectonics: A review and new experimental results. Tectonophysics, 574-575:1-71

Edmonds M. 2008. New geochemical insights into volcanic degassing. Philosophical Transactions of the Royal Society A, 366:4559-4579.

Fernandes L.A.D., Tommasi A., Porcher C.C. 1992. Deformation patterns in the Southern Brazilian branch of the Dom Feliciano Belt: A reappraisal. Journal of South American Earth Sciences, 5:77-96.

Fernandes L.A.D., Menegat R., Costa A.F.U., Koester E., Porcher C.C., Tommasi A. Kraemer G. Ramgrab G.E. Camozzato E. 1995. Evolução tectônica do Cinturão Dom Feliciano no Escudo Sul-rio-grandense: parte I - Uma contribuição a partir do registro geológico. Revista Brasileira de Geociências, 25(4):351-374

Frost B.R., Barnes C.G., CollinsW.J., Arculus R.J., Ellis D.J., Frost C.D. 2001. A geochemical classification for granitic rocks. Journal of Petrology, 42:2033-2048

Gastal M.C. Teixeira W., Lafon J.M. Remus M.V.D. 2005. Geocronologia ${ }^{40} \mathrm{Ar} /{ }^{40} \mathrm{Ar},{ }^{207} \mathrm{~Pb} /{ }^{206} \mathrm{~Pb}$ e ${ }^{207} \mathrm{~Pb} / 238 \mathrm{U}$ do complexo intrusivo Lavras do Sul, RS. In: 30 Simpósio de Vulcanismo e Ambientes Associados. Cabo Frio, Resumo expandido, 6p.

Gastal M.C., Lafon J.M., Ferreira F.J.F., Magro F.U.S., Remus M.V.D., Sommer C.A. 2006. Reinterpretação do Complexo Intrusivo 
Lavras do Sul - RS, de acordo com os sistemas vulcano-plutônicos de subsidência. Parte I: Geologia, geofísica e geocronologia ${ }^{207} \mathrm{~Pb} / 206 \mathrm{~Pb}$ e $\left.{ }^{206} \mathrm{~Pb} / 238 \mathrm{U}\right)$. Revista Brasileira de Geociências, 36:109-124.

Gastal M.C., Lafon J.M., Chemale Jr. F. 2010. U-Pb and Pb-Pb zircon ages of Neoproterozoic-Eopaleozoic granites from the western portion of the southern Brazilian Shield. In: 70 Southern America Symposium on Isotope Geology. Brasília. Extended Abstracts, 4 p.

Grohmann C.H. \& Campanha G.A.C., 2010. OpenStereo: open source, cross-platform software for structural geology analysis. Presented at the AGU 2010 Fall Meeting, San Francisco, CA.

Hancock P.L. 1985. Brittle microtectonics: principles and practice. Journal of Structural Geology, 7:437-457

Hippolyte J.C., Bergerat F., Gordon M.B., Bellier O., Espurt N. 2012. Keys and pitfalls in mesoscale fault analysis and paleostress reconstructions, the use of Angelier's methods. Tectonophysics, 581:144-162.

Holohan E.P., van Wyk de Vries B., Troll V.R. 2008. Analogue models of caldera collapse in strike-slip tectonicregimes. Bulletin of Volcanology, 70:773-796.

Janikian L., Almeida R.P., Trindade R.I.F., Fragoso Cesar A.R.S., D’Agrella fl.M.S., Dantas E.L., Tohver E. 2008. The continental record of Ediacaran volcano-sedimentary succession in southern Brazil and their global implications. Terra Nova, 20:259-266.

Johnson S.E., Schmidt K.L., Tate M.C. 2002. Ring complexes in the Peninsular Ranges Batholith, Mexico and the USA: magma-plumbing systems in the middle and upper crust. Lithos, 61:187-208.

Kaul P.F.T. \& Rheinheimer D. 1974. Projeto Ouro no Rio Grande do Sul e Santa Catarina. Porto Alegre, DNPM/CPRM, v.1, 372 p.

Kennedy B. \& Stix J. 2007. Magmatic processes associated with caldera collapse at Ossipee ring dyke, New Hampshire. Geological Society of America Bulletin, 119:3-17.

Kennedy B., Wilcock J., Stix J. 2012. Caldera resurgence during magma replenishment and rejuvenation at Vallesand Lake City calderas. Bulletin of Volcanology, 74:1833-1847.

Kloppenburg A., Grocott J., Hutchinson D. 2010. Structural setting and synplutonic fault kinematics of a Cordilleran $\mathrm{Cu}-\mathrm{Au}-\mathrm{Mo}$ porphyry mineralization system, Bingham Mining District, Utah. Economic Geology, 105:743-761.

Lima E.F. 1995. Petrologia das rochas vulcânicas e hipoabissais da Associação Shoshonítica de Lavras do Sul, RS. PhD Thesis, Instituto de Geociências, Universidade Federal do Rio Grande do Sul, Rio Grande do Sul, 338p.

Liz J.D., Lima E.F., Nardi L.V.S., Sommer C.A., Saldanha D.L., Pierosan R. 2009. Petrologia e sucessão estratigráfica das rochas monzoníticas da associação shoshonítica de Lavras do Sul (RS). Revista Brasileira de Geociências, 39:244-255.

Marret R. \& Allmendinger R.W. 1990. Kinematic analysis of fault-slip data. Journal of Structural Geology, 12:973-986.

Marsh B.D. 2000. Magma chambers. In: Sigurdsson H. (ed.). Encyclopedia of Volcanoes, San Diego, Academic Press, p. 191-206.

Milligan P.R. \& Gunn P.J. 1997. Enhancement and presentation of airborne geophysical data. AGSO Journal of Australian Geology and Geophysics, 17:63-75.

Nabighian M.N., Grauch V.J.S., Hansen R.O., LaFehr T.R., Li Y., Peirce J.W., Phillips J.D., Ruder M.E. 2005. The historical development of the magnetic method in exploration. Geophysics, 70:33ND-61ND.
Nardi L.V.S. 1984. Geochemistry and Petrology of the Lavras Granite Complex, RS, Brazil. PhD Thesis, Department of Geology King's College, University of London, London, 268p.

Nardi L.V.S. \& Lima E.F. 1988. Hidrotermalismo no Complexo Granítico Lavras e vulcânicas associadas. Revista Brasileira de Geociências, 18:269-375.

Petford N., Cruden A.R., McCaffrey K.J.W., Vigneresse J.L. 2000.Granite magma formation, transport and emplacement in the Earth's crust. Nature, 408:669-673.

Petit J.P. 1987. Criteria for the sense of movement on fault surfaces in brittle rocks. Journal of Structural Geology, 9:597-608.

Pirajno F. 2010. Intracontinental strike-slip faults, associated magmatism, mineral systems and mantle dynamics: examples from NW China and Altay-Sayan (Siberia). Journal of Geodynamics, 50:325-346.

Porcher C.A. \& Lopes R.C. 2000. Programa Levantamentos Geológicos Básicos do Brasil - PLGB: Cachoeira do Sul (folha SH.22-Y-A), Porto Alegre, CPRM/DNPM (CD-ROOM).

Prelevic D., Foley S.F., Romer R.L., Cvetkovic V., Downes H. 2005. Tertiary ultrapotassic volcanism in Serbia: Constraints on petrogenesis and mantle source characteristics. Journal of Petrology, 46:1443-1487

Raposo M.I.B. \& Gastal M.C. 2009. Emplacement setting of the granite pluton of the Lavras do Sul Intrusive Complex (Rio Grande do Sul State), south Brazil: Determined by magnetic anisotropies. Tectonophysics, 466:18-31

Reischl J.L. 1978. Mineralizações cupríferas associadas a vulcânicas na Mina Seival - RS. In: $30^{\circ}$ Congresso Brasileiro de Geologia, Anais, v. 4, p.1568-1582.

Remus M.V.D., Hartmann L.A., McNaugton N.J., Groves D.I., Reischl J.L. 2000. Distal magmatic-hydrothermal origin for the Camaquã $\mathrm{Cu}(\mathrm{Au}-\mathrm{Ag})$ and Santa Maria Pb, Zn (Cu-Ag) deposits, southern Brazil. Gondwana Research, 3(2):155-174.

Ribeiro M., Bocchi P.R., Figueiredo Filho P.M., Tessari R.I. 1966. Geologia da quadrícula de Caçapava do Sul, RS. Boletim do Departamento Nacional da Produção Mineral, Divisão de Geologia e Mineralogia, v. 127, 232 p.

Ribeiro M.J. 1978. Mapa previsional do cobre no Escudo Sul-riograndense. Nota Explicativa. Departamento da Produção Mineral, Brasília. Série Geologia, v. 3, 104 p.

Richards J.P. 2009. Postsubduction porphyry Cu-Au and epithermal $\mathrm{Au}$ deposits: Products of remelting of subduction-modified lithosphere. Geology, 37:247-250.

Roberts J.L. 1970. The intrusion of magma into brittle rocks. In: Newall G. \& Rast N. (eds.). Mechanism of Igneous Intrusion. Geological Journal, Special Issues,2:287-338.

Roldão D.G. 2000. Análise integrada de dados estruturais e geofísicos no controle de depósitos minerais na região oeste do Escudo Sul-riograndense. MS Dissertation, Escola de Engenharia, Universidade Federal do Rio Grande do Sul, Rio Grande do Sul, 133p.

Saunders S.J. 2005. The possible contribution of circumferential fault intrusion to caldera resurgence. Bulletin of Volcanology, 67:57-71.

Shabanian E., Acocella V., Gioconda A., Ghasemi H., Bellier O. 2012. Structural control on volcanism in intraplate post collisional settings: Late Cenozoic to Quaternary examples of Iran and Eastern Turkey. Tectonics, 31:TC3012. 
Silva L.C., McNaughton N.J., Armstrong R., Hartmann L.A., Fletcher I.R. 2005. The neoproterozoic Mantiqueira Province and its African connections: a zircon-based U-Pb geochronologic subdivision for the Brasiliano/ Pan-African systems of orogens. Precambrian Research, 136:203-240.

Sillitoe R.H. 2010. Porphyry copper systems. Economic Geology, 105:3-41.

Smith R.L. \& Bailey R.A. 1968. Resurgent cauldrons. In: Coats R.R., Hay R.L., Anderson C.A. (eds.). Studies in Volcanology. Geological Society of America Memoir, 116:613-662.

Stevenson C.T.E., O'Driscoll B., Holohan E.P., Couchman R., Reavy R.J., Andrews G.D.M. 2008. The structure, fabrics and AMS of the Slieve Gullion ring-complex, Northern Ireland: testing the ring-dyke emplacement model. The Geological Society, London, Special Publications, 302:159-184.
UFRGS. 2003. Mapa Geológico de Parte da Folha Arroio América SH-22-Y-A-IV-1 (MI 2995/1). Trabalho de mapeamento, Instituto de Geociências da Universidade Federal do Rio Grande do Sul, Rio Grande do Sul.

UFRGS. 2004. Mapa Geológico de Parte da Folha Lavras do Sul SH-22-Y-A-IV-3. Trabalho de mapeamento, Instituto de Geociências da Universidade Federal do Rio Grande do Sul, Rio Grande do Sul.

Vaughan A.P.M. \& Scarrow J.H. 2003. K-rich mantle metasomatism control of localization and initiation of lithospheric strike-slip faulting. Terra Nova, 15:163-169.

Arquivo digital disponível on-line no site wwww.sbgeo.org.br 